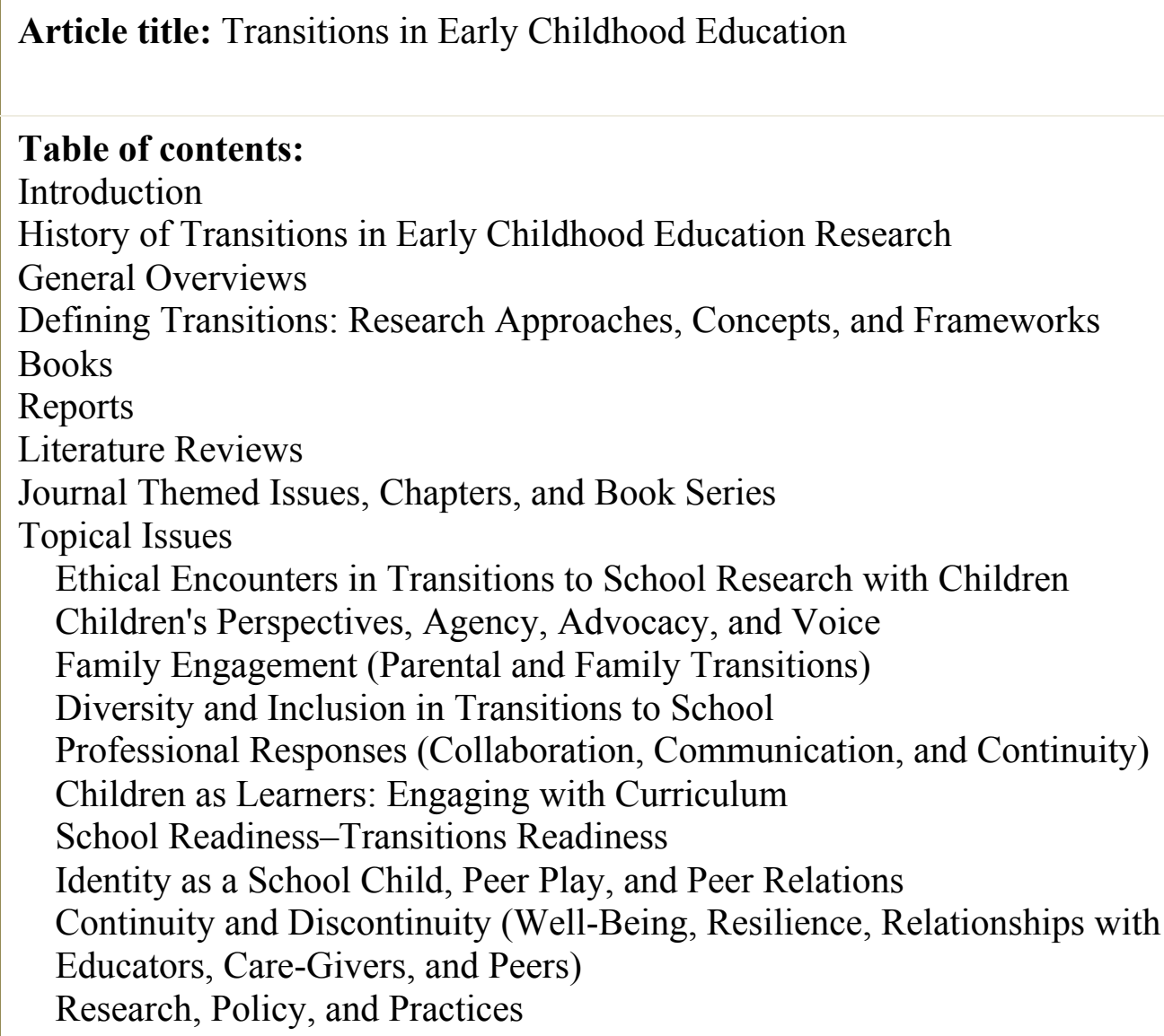

\title{
TRANSITIONS IN EARLY CHILDHOOD EDUCATION
}

\section{INTRODUCTION}

Transitions are ubiquitous: they start as our lives begin and we all experience them as we travel the life-course. In the context of early childhood (UN Convention on the Rights of the Children, UNCRC: $0-8$ ) the single transition that has attracted the most attention has been the transition to school. In today's society children have often experienced many changes before reaching this moment of school start: in educational and academic circles these changes are often described as transitions and so it is essential that the term "transition" is defined. The child does not function 
in isolation from family or community and models held of children influence approaches to their early learning and childcare. It is therefore important to address the nature of transition and the ways in which transitions in life may affect transitions in early childhood education and viceversa. A range of issues challenges definition of transition: it is suggested here that these issues have become more complex over the historical time in which transitions have been studied. It may be argued that there has been considerable consensus over the years about what may matter in early childhood educational transitions, but this is no longer without debate or challenge. The contested issues are frequently presented in a dichotomous way. Transitions may be single or multiple; continuous or discontinuous; suggest readiness or lack of it; highlight resilience or vulnerability; imply agency or lack of control; be visible or silenced; rest on a developmental or a sociocultural model; may infer that the child should be the site of change or conversely that the system should change to accommodate the child. Multiple perspectives are called for as the child in transition is variously understood in the context of family, relationships, identities, culture, services, and community. For a considerable time Bronfenbrenner's ecological systems theory was the most commonly invoked conceptual framework for the study of transitions in early education. Now other theoretical sources are being used: researchers draw on, for example, anthropology, educational theory, creativity, philosophy, and psychology and consequently new approaches and paradigms are developing. Transition in early childhood education has become a field of study in its own right. Findings of transition studies argue for acknowledgement of young children's experience before, during, and after any time of transition and illustrate the many ways in which current systems shape children's experiences. The understanding generated by research into early childhood educational transitions and the processes involved, must reach into policy and practices: a job done very well by many of the authors cited in this article 


\section{HISTORY OF TRANSITIONS IN EARLY CHILDHOOD EDUCATION RESEARCH}

This section places research into transitions in early childhood education in context by introducing some of the earlier studies of school start. These studies focused more on continuity in early education: concluding that contextual constraints on children's use of learning strategies made for discontinuities. As understanding grew of the limitations the move through different educational systems placed on the continuity of children's learning, what was to become a field of research in its own right, research into early educational transitions, emerged. This emerging focus seemed promising in both pastoral and curricular terms. Three pieces of work-from England (Cleave 1982), Scotland (Watt 1985), and the United States (Ladd and Price 1987)_illustrate the early beginnings of a transitions focus and a range of linked factors. A number of innovative studies began to shape the field further in the 1990s including continuity to maximize the benefits of preschool (Love, et al. 1992), the importance of early learning, continuities, and discontinuities (Cullen 1992), and opportunities to develop positive learning trajectories and recognize what children bring to school in terms of their socio-emotional dispositions and their family experiences (Belsky and MacKinnon 1994). Belsky and MacKinnon 1994 found it surprising that beyond the work of Entwisle and Alexander 1998 (cited under *Children as Learners*) and their colleagues and a very few others, transition to school was at the time underresearched. In Europe there was a growing interest in transitions issues, as evidenced by each of the following: the effectiveness of strategies smoothing the transitions to school (Kakvoulis 1994), the role of the teacher (McCail 1996, cited under *Children as Learners*), assessment for continuity (Dunlop 1998, cited under *Continuity and Discontinuity [Well-Being, Resilience, Relationships with Educators, Care-Givers, and Peers]*), young children's views (see

*Children's Perspectives*), parental and child views (Hughes 2015, cited under *General 
Overviews*), and work on the connection between family transitions and school start (Fthenakis 1998, cited under *Family Engagement (Parental and Family Transitions)*. Also see Alexander and Entwisle 1998, cited under *Children as Learners*, and the section *Inclusion in Transitions to School*). Nine articles published before 1996 are included here, the others are referenced in subsequent sections, but mentioned here to give a taste of the range of early work in transitions and showing the continuing relevance of the multidimensional nature of early childhood transitions.

Belsky, Jay, and Carol MacKinnon. 1994. Transition to school: Developmental trajectories and school experiences. Early Education and Development 5.2: 106-119. [class:journalArticle] This article highlights the premium placed on developmental transitions and calls for a move away from a narrow school-readiness orientation to a recognition of the changes in role, expectations, relationships, and physical environments that occur in the transition to early schooling, a topic that was relatively under-researched at the time.

Cleave, Shirley. 1982. Continuity from pre-school to infant school. Educational Research 24.3: 163-173. [class:journalArticle]

Summarizing a major National Foundation for Educational Research project on continuity of children's experience, ages three to eight, this article emphasizes the significance of early relationships and identifies the interruptions likely to occur for children as they move from stage to stage: critical features of continuity included admission and entry processes; arrival and familiarity; visits before starting; building relationships; adjusting to novel experiences; work tasks and activities; and changing routines.

Cullen, Joy. 1992. Young children's learning strategies: continuities and discontinuities. International Journal of Early Childhood 23.1: 44-58. [class:journalArticle] 
While much emphasis had already been placed on positive school start in terms of relationships, Joy Cullen importantly focused attention in Australia on young children's learning strategies. Children whose approach to learning at preschool was characterized by a range of strategic behaviors and reflective skills maintained a strategic approach to learning in their first year at school.

Entwisle, Doris, and Karl Alexander. 1998. Facilitating the transition to first grade: The nature of transition and research on factors affecting it. The Elementary School Journal 98.4: 351-364. Drawing on the Baltimore Study, the authors identified a random sample of 790 children who began first grade in 1982: their longitudinal study of this group, they emphasize the importance of the first grade transition, offer practical suggestions and underline the role of resident grandmothers, more time in kindergarten and school continuity for children's success.

Kakvoulis, Alexandros. 1994. Continuity in early childhood education: Transition from preschool to school. International Journal of Early Years Education 2.1: 41-51.

[https://doi.org/10.1080/09669760.2003.10807105] [class:journalArticle]

A Greek investigation surveyed three stakeholder groups: parents, preschool and primary teachers on the extent to which differences between home and primary school or between nursery school and primary school make children's preparation and adjustment to the first class problematic, and evaluated the claimed effectiveness of strategies for smoothing the transition to school.

Ladd, Gary W., and Joseph M. Price. 1987. Predicting children's social \& school adjustment following the transition from preschool to kindergarten. Child Development 58:1168-1189. [class:journalArticle] 
The relevance of this and many useful articles by these authors sustain today. They studied a sample of children in their year before school entry and followed them up in school. Finding that children's social characteristics are a strong influence on their school experience they advocate assessing more than intelligence before school entry.

Love, John M., Mary Ellin Logue, James V. Trudeau, and Katharine Thayer. 1992. Transitions to kindergarten in American schools. Final report of the National Transitions Study. Portsmouth, NH: U.S. Department of Education, Office of Policy and Planning. [class:bookChapter] The results of this study of early transitions are given through a report of the National Transition Study, a government document. As such it does not explore the conceptual underpinnings of cultural, social-poverty, and language differences, but provides a clear set of statements of what is known in these areas and calls for differentiating transitions for these groups of children. Pianta, Robert C., Nicholas Smith, and Ronald E. Reeve. 1991. Observing mother and child behavior in a problem-solving situation at school entry: Relations with classroom adjustment. School Psychology Quarterly 6:1-15. [class:journalArticle]

An early publication from Pianta's research team, which continues to publish on transitions today, this paper provides an early acknowledgement of the richness of observational rather than assessment data to understand cognition, motivation, exploration, and social school relationships. These elements in ecological relationships illuminate children's school entry profiles.

Watt, Joyce, and Marion Flett. 1985. Continuity in early education: The role of parents. Mimeo: Univ. of Aberdeen, Department of Education.

Another theme in early transitions writing is the role of parents in continuity. They must play a part in the child's early years and early school experience. Parents support children to 
communicate what they know in different settings. Parental self-respect is found to be significant for their child's learning.

\section{GENERAL OVERVIEWS}

For anyone making a start in searching for information about transitions in early childhood education a definition of transitions is needed. Fabian and Dunlop 2002 (cited under *Reports*) offer us "a dynamic time of change" and "accelerated developmental demands," while as early as 1998, three decades into transitions research, Kagan and Neuman 1998 embraces the situations in which change within the child occurs but combines developmental change with ecological factors: for the authors transition is "the manifestation of the developmental principles of continuity, that is, creating pedagogical, curricular, and/or disciplinary approaches that transcend, and continue between, programs" (p. 1). There are a number of readily accessible journal articles that provide an overview of trends in research and practice and make suggestions for future work, for example Petriwskyj, et al. 2005 which considers trends in transitions. Given the breadth of this field of work that now spans five decades, there are also many briefer summaries of evidence on the state of transitions research. Two such examples are included here: Hughes 2015 provides a psychological perspective, while Cartmell 2011 offers an educational view. Dockett and Perry 2013, whose authors are academic researchers and prolific writers, bridges research, policy, and practices on transitions to school, while addressing a range of perspectives including parental, professional, and children's voice. Along with other authors, their work also addresses a number of other topics identified in the present article. In this growing field of research there are clear trends, and not so many tensions between researchers, though the interest in and continuing need for this kind of work over the decades raises questions about the impact of research (see * Research, Policy and Practices*), especially when it is so 
rooted in the field it explores. Bohan-Baker and Little 2002 details promising practices in transition and points to earlier research which argued that early intervention cannot be considered as "an inoculation" guaranteeing later success in school—how positive learning, development, and achievements are sustained during transitions is worthy of consideration. We have to ask whether school structures and systems are too static over time, despite early childhood and early school curriculum reform in many countries internationally, thus, as Skouteris, et al. 2012 does, raising issues of partnership and collaboration between sectors. Bohan-Baker, Marielle, and Patricia M. D. Little. 2002. The transition to kindergarten: A review of current research and promising practices to involve families. Cambridge, MA: Harvard Family Research Project. [class:book]

This review is included to highlight what the authors refer to as "promising practices" suited to transitions being both dynamic and ecological. In recognizing the many domains implicated in continuity, they focus particularly on family involvement as a transitions mechanism: social and economic factors being predictive of educational success.

Cartmell, Katherine M. 2011. Educational transitions within the UK: What is known and what needs to be investigated? The Psychology of Education Review 35.1: 27-32.

[class:journalArticle]

Reporting on the "UK" Cartmell is, in fact, writing about the English system. She describes early transitions research as stagnant and "no longer applicable" although most of her references illustrating transitions' factors date pre-2003. She recommends, but seems unaware, that much transitions work focuses upon interrelated sets of systems. 
Dockett, Sue, and Bob Perry. 2013. Trends and tensions: Australian and international research about starting school. International Journal of Early Years Education 21.2-3: 163-177. [https://doi.org/10.1080/09669760.2013.832943] [class:journalArticle]

The trends and tensions of the title can be located in identifying the differences between two contrasting models of school start: a child-readiness model and a narrow school program model, the authors argue well for combining and widening each to take account of context, cultural relevance, and relationship-building.

Hughes, Claire. 2015. *The transition to school[http://thepsychologist.bps.org.uk/volume28/september-2015/transition-school]*. The Psychologist 28:714-717. [class:journalArticle] Early childhood has captured the attention of policymakers attempting to make a difference to long-term outcomes: Hughes brings together the importance of three transitions factors: cognitive support, emotional support, and autonomy support. She writes about the non-linearity of parental effects and shows the importance of fostering family routines. Kagan, Sharon L., and Michelle J. Neuman. 1998. Three decades of transitions research. The Elementary School Journal Special Issue: Transitions 98.4: 365-379. [class:journalArticle] This watershed review emphasizes the importance of continuity in children's lives and questions "the long-term efficacy of early intervention without successful transition" (p. 366). The authors advocate that transitions researchers must be pro-active in developing new research methods and influencing policy and practices in ensuring successful transitions in early childhood.

Petriwskyj, Anne, Karen J. Thorpe, and Collette P. Tayler. 2005. Trends in construction of transition to school in three western regions, 1990-2004. International Journal of Early Years Education 13.1: 55-69. [https://doi.org/10.1080/09669760500048360] [class:journalArticle] 
The weaving of continuity and transitions issues emerged from this review of seventy-five academic publications. In particular the imbalance in school-parent relationships leaves parents marginalized and calls for a more complex meshing of the role of schools and education: framing continuity as communication, coherence of experience, and of systems.

Skouteris, Helen, Brittany Watson, and Jarrad Lum. 2012. Preschool children's transition to formal schooling: The importance of collaboration between teachers, parents and children. Australasian Journal of Early Childhood 37.4: 78-85. [class:journalArticle]

Pedagogical differences between approaches on either side of a child's transition do not serve children well. This overview of the effects of improved pedagogical cooperation across sectors of early childhood will support a changed vision of teachers and parents working together to help children in transition and shape their futures.

Yeboah, David A. 2002. Enhancing transition from early childhood phase to primary education: Evidence from the research literature. Early Years 22.1: 51-68.

[https://doi.org/10.1080/09575140120111517] [class:journalArticle]

As with others who review this extensive literature, Yeboah finds there is adequate evidence to assert the importance of transition to school: he offers twenty principles of successful transition which remain relevant today for transitions planning toward children's future progress and place in their community: socially and economically.

\section{DEFINING TRANSITIONS: RESEARCH APPROACHES, CONCEPTS, AND FRAMEWORKS}

In seeking to frame transitions studies conceptually, an understanding grew among researchers that neither developmental nor environmental views offered a complete understanding of children's lives. This section offers frameworks from developmental philosophy, psychology, 
sociology, ethnography, critical pedagogy, family theory, anthropology, life-course theory, and ecology of human development. Many researchers use Bronfenbrenner's 1979 ecological systems theory and its subsequent iterations. These iterations acknowledged that there were failures to make adequate connections across the domains of development and environment and between systems, and have provided transitions researchers with a powerful, though not the only, tool for interpreting transitions. Importantly Bronfenbrenner 2005 stated that the "developmental importance of ecological transitions derives from the fact that they almost invariably involve a change in role" (p. 53). A number of authors made explicit use of this model including Pianta's early work (Pianta and Cox 1999, cited under *Books*). Bronfenbrenner 2005 asserted that ecological transitions were a site or process of (until then) "untapped research potential” (p. 53). Some of the earliest transitions studies date from those years, though they were not identified by the researchers of the time as explicitly ecological. In fact, as described in *History of Transitions* there was a swell of such work across the globe, but little connection between the separate initiatives, evidence perhaps that Western systems of education were not taking sufficient cognizance of children's prior learning and experience. Cowan 1991, in one of the early definitions of transitions, captures this interaction of development and environments when the author states: "We view transitions as occurring when there are qualitative shifts in the individual's self-concept and world view, major life roles, and central relationships." Other definitions have been included in the *General Overviews* commentary. With changes in role come changes in status and identity: agency and voice need to accompany such changes. Elder 1998 (Lifecourse Theory), Sameroff 2009 (Transactional Model of Development), and Bourdieu's theories of social and cultural capital (Davey 2009) recognize that forms of pedagogy and ways of learning are all implicated in studies of early educational transitions. Researchers 
and writers have also drawn on reconceptualizing models, on postmodernist thinking (Giroux 2005), and on the affordances of boundary crossing and boundary objects as reviewed by Akkerman and Bakker 2011 as well as materials and environments. There are a number of studies that draw different theories together in new conceptual frameworks, for example Brooker 2002 (cited under *Ethical Encounters*).

Akkerman, Sanne, and Arthur Bakker. 2011. Boundary crossing and boundary objects. Review of Educational Research 81.2: 132-169. [class:journalArticle]

The work presented here reviews the concept of boundaries: applied to a variety of contexts in the cited article, it may also be applied to boundary crossing in school transitions: a third dialogical (as in Bahktin) and "in between" space opens up a site for potential learning and change.

Bronfenbrenner, Urie, and Stephen J. Ceci. 1994. Nature-nurture in developmental perspective: A bioecological theory. Psychological Review 101:568-586. [class:journalArticle] Bronfenbrenner's groundbreaking Ecology of Human Development bridged previously separated disciplines, such as sociology and anthropology: consequently child development is understood in terms of family, school, community and society, highlighting ecological transitions. This paper expands earlier work to produce an empirically testable theoretical model embracing proximal process and the environment.

Corsaro, William. 1996. Transitions in early childhood: The promise of comparative, longitudinal, ethnography. In Ethnography and human development. Edited by Richard Jessor, Anne Colby, and Richard A. Shweder, 419-457. Chicago: Univ. of Chicago Press. [ISBN: 9780226399034] [class:bookChapter] 
A unique and important contribution to the study of early childhood transitions: Corsaro's interpretative approach challenges traditional positivist longitudinal studies and argues for "intensive, continuous and often microscopic observation" (p. 412). His respect for children's experience, their cultural contexts and immersion therein remains a challenge for contemporary “children's perspective" transitions research.

Cowan, Philip A. 1991. Individual and family life transitions: A proposal for a new definition. In Advances in family research series. Family transitions. Edited by P. A. Cowan \& E. M. Hetherington, 3-30. Hillsdale, NJ: Lawrence Erlbaum.

One of the more helpful definitions of transitions that widened existing approaches that had defined transitions differently for children and adults, Cowan sought to "do justice" to a lifecourse concept of transitions. Subsequently this view has influenced researchers: particularly those studying transitions over time.

Cowan, Philip A., Carolyn Pape Cowan, Jennifer C. Ablow, Vanessa K. Johnson, and Jeffrey R. Measelle, eds. 2005. The family context of parenting in children's adaptation to elementary school. Mahwah, NJ: Lawrence Erlbaum. [ISBN: 9780805841572] [class:bookChapter] Seen as a key determinant of children's adaptation to school, family influences within the context of the family system provide important arguments for including parental influences and perspectives in transitions study design. Their five domain contextual model includes within family relationships (child, couple, and generationally) and external stressors and supports. Davey, Gayna. 2009. Using Bourdieu's concept of habitus to explore narratives of transition. European Education Research Journal 8.2: 276-284.

[http://dx.doi.org/10.2304/eerj.2009.8.2.276] [class:journalArticle] 
Davey finds that a Bourdieuian framework offers a fluid, dynamic, and multidimensional way of looking at continuity and change in lives. She considers habitus, $\mathrm{f}$ and capital and explores narratives of transition. Where habitus and cultural capital are considered together they provide tools for change in the process of transition.

Elder, Glen H., Jr. 1998. The Lifecourse as developmental theory. Child Development 69.1: 1-

\section{2. [class:journalArticle]}

Elder considers the implications of successive life transitions that form trajectories beginning in the early years. His principles of "historical time and place," "timing in life," "linked lives," and "human agency," provide a succession of "choice points" in transitions, and the possibility of studying "lives in motion" through networks of relationships.

Garpelin, Anders. 2014. Transition to school: A rite of passage in life. In Transitions to school, international research, policy and practice. Edited by Bob Perry, Sue Dockett, and Anne Petriwskyj, 117-128. Dordrecht, The Netherlands: Springer. [ISBN: 9789400773509] [class:bookChapter]

Garpelin's work frames transitions anthropologically, in this recent iteration of Van Gennep's "rites of passage," he uses the metaphor of the "threshold" to indicate the changes in status that occur in childhood transitions and "borderland"- the spaces in between, as a shared site for mutual understanding from each side of transition.

Giroux, Henry. 2005. Cultural studies. Resisting difference, and the return of critical pedagogy. In Border crossing: Cultural workers and the politics of education. $2 \mathrm{~d}$ ed. Edited by Henry A Giroux, 137-155. New York: Routledge. [ISBN: 9780415951487] [class:bookChapter] Giroux's writing on the impact of ideologies, on "contradictory voices and lived experiences" (p. 24) means critical pedagogy is helpful in questioning the nature of transitions. He advocates 
taking experience on a detour through knowledge and theory. A critical pedagogy supports the interrogation of the different spaces and cultures experienced by children in transition through early childhood.

Sameroff, Arnold. 2009. "The transactional model of development." How children and contexts shape each other. Edited by Arnold Sameroff. Washington, DC: American Psychological Association. [ISBN: 9781433804670] [class:book]

Sameroff asserts that to recognize changes or discontinuities, we also have to recognize continuities. His model of development captures the mutual and transactional influence of child and environment. Times of transition expose children and those who engage with them in new developmental trajectories, as this book illustrates.

\section{BOOKS}

This section provides a selection of eight books, six of which are edited volumes with a range of authors and all of which have a strong evidence base drawn from research and applied to both policy and practice. Many chapter authors draw on ecological systems theory and its developments: a background to this and other theoretical underpinnings to transitions research are offered in the *Defining Transitions* section. Pianta and Cox 1999 ("The Transition to Kindergarten") is introduced with a discussion of the ecological nature of transition. Pianta remains a proponent of such a theoretical frame. Readers may find it useful to identify publishers too: Springer has a research-based book series on transitions, the latest of which is Dockett, et al. 2017 on families and the transition to school (cited under *Family Engagement [Parental and Family Transitions]*) and resources under *Journal Themed Issues, Chapters, and Book Series*. The Springer series also publishes on transitions in learning, for example in mathematics. Such series combine practice-based research with research-based practices and supports continuing 
professional development as well. On the other hand many "advice books" are also available: the evidence for these is based more on educators' practice and therefore are not included in this review which focuses more on the interplay between practices, scholarship, research, and policy as arguably inseparable agents for learning, development, and change. It is a function of research to understand and build on practice evidence so that understandings of transitions are informed in a two-way relationship of evidence-based practices and practice-researched evidence. The books included here are all therefore research informed. Ballam, et al. 2017 worked on an edited volume based on the themes of the Pedagogies of Educational Transitions (POET) Alliance: this group generated much new thinking about diversity and inclusion, indigenous children's transitions, continuity and change at school start, transitions as border crossing, bridging and rites of passage, and transitions as tools for change in early educational transitions. Margetts and Kienig 2013 also brings together a range of well researched and evidenced work which aimed to reconceptualize transitions, while Brooker 2008 and Corsaro and Molinari 2005 offer rich thinking about transitions, the interpersonal relationships, and in Brooker's case not only educational transitions. Three other co-edited books are included: the trends identified in Pianta and Cox 1999 are well-connected to later works, including Dunlop and Fabian 2007 which informs research, policy, and practice; Laverick and Jalongo 2011 aims to look at how systems could be more ready for children, while Rayna and Garnier 2017 is one of a series of books on transitions for the very youngest children that brings together an international group of attendees at their 2015 Paris conference on transitions. The currency of all of these books, older and very recent, makes a powerful contribution to the field. 
Ballam, Nadine, Bob Perry, and Anders Garpelin, eds. 2017. Pedagogies of educational transitions. European and Antipodean research. Cham, Switzerland: Springer International. [ISBN: 9783319431161] [class:book]

The authors participated in a five-country, four-year shared journey through an International Research Staff Exchange Scheme from 2013-2016. Country projects generated significant new research-based thinking. Emerging threads for further research are: transition as a social experience, individual change and transitions journeys, transition and precariousness, and pedagogical responsibility.

Brooker, Liz. 2008. Supporting transitions in the early years. Maidenhead, UK: Open Univ. Press/McGraw-Hill. [ISBN: 9780335221684] [class:book]

The beauty of this book lies in the way in which it addresses many of the transitions children make in early childhood, rather than only focusing on one. Abiding concepts apply right across these early experiences: principally child, practitioner, and parental agency as we share and influence leadership in transitions.

Corsaro, Bill, and Luisa Molinari. 2005. I Compagni: Understanding children's transition from preschool to elementary school. Sociology of Education Series. New York and London: Teachers College Press. [ISBN: 9780807746189] [class:book] The commitment to ethnographic immersion in the daily life of preschool and elementary school generated rich insights, in work by these authors, into children's interpersonal creation of culture, friendships, creativity, and knowledge when adults find a balance of space, time, support, and embedded priming events for children's ventures and transitions. 
Dunlop, Aline-Wendy, and Hilary Fabian, eds. 2007. Informing transitions in the early years: Research, Policy and Practice. Maidenhead, UK: Open Univ. Press/McGraw Hill. [ISBN: 9780335229703] [class:book]

The third of three co-edited international collections makes connections between research, policy, and practices. Moving beyond conceptualizing transitions as linear, vertical, and horizontal the conclusions envisage the complex and dynamic nature of early childhood transitions over time. Innovative concepts of transitions capital and transitions as tools for change are introduced.

Laverick, DeAnna M., and Mary R. Jalongo, eds. 2011. Transitions to early care and education: International perspectives on making schools ready for young children. Dordrecht, The Netherlands, and New York: Springer. [ISBN: 9789400705722] [class:book]

The intention of this book is to advocate and illustrate ways of making early childhood transitions as smooth and continuous as possible, not least by ensuring that out-of-home settings and practitioners are ready for the diversity of children and families that cross the threshold from babyhood until school start.

Margetts, Kay, and Anna Kienig, eds. 2013. International perspectives on transition to school: Reconceptualising beliefs, policy and practice. Abingdon, UK: Routledge. [ISBN: 9780415536127] [class:book]

The chapters are grouped under four important themes: policy, curriculum frameworks, and practice; outcomes for children and children's perspectives; roles, expectations, and experiences of families; and reframing transitions and curriculum. The editors challenge the "silences" and continuing gaps in understanding transitions. They seek to reconceptualize transitions in a sociocultural framework. 
Pianta, Robert C., and Martha J. Cox, eds. 1999. The transition to kindergarten. Baltimore: Paul Brookes. [ISBN: 9781557663993] [class:book]

Included as one of the earliest background readers on transitions to kindergarten, the final chapter brings together trends for the next decade - trends of accountability, diversity, universal preschool provision, and the integration of developmental psychology and education. Still contemporary issues today, transitions are grounded in an ecological perspective. (Digitalized, 2010).

Rayna, Sylvie, and Pascale Garnier, eds. 2017. Transitions dans la petite enfance. Recherches en Europe et au Québec. Brussels: Peter Lang. [ISBN: 9782807602694] [class:book]

This French-language publication looks particularly at transitions and socialization in the youngest children. Given much research is focused on starting preschool or school it is timely to have a collection of chapters on crèches, childminding, parental roles, and micro-transitions across the crèche day. Some English-language versions available *online[https://hal-univparis13.archives-ouvertes.fr/PETITE-ENFANCE]*, see the tab "Consulter les dépôts."

\section{REPORTS}

In practice terms, there has been a growing awareness and concern that the provision of early childhood education and care does not translate into a seamless experience for every child. Families are the most consistent providers of continuity for children. Continuity of relationships is acknowledged in research to be important to children's school success, and there is evidence in the research literature that continuity in learning also matters. The disjunctions in systems, in staffing, in funding, in ratios of adult to child, in ways of thinking about children, in pedagogy, and in environments mean that the tools of curriculum reform and curriculum alignment between sectors fail as yet to provide continuity of educational experience. There is a growing 
understanding that there are failures to make adequate connections across both conceptual and practical boundaries of disciplines and educational sectors, leading to a growing awareness in policy fields that a greater understanding is needed of what is happening in the major changes children make on their educational journeys. Thus over time reports into transitions have been commissioned by governments, including: Dockett and Perry 2014; the EU-Agency's Early Years Transition's Programme 2010; and those funded by research initiatives such as Peters, et al. 2015 (Teaching and Learning Research Initiative Report). In the United States the policy goal that no child should be left behind brought about new investments in efforts to understand educational and personal journeys, including Kagan and Rigby 2003, presenting work on readiness for school and a new lens on what advantages or disadvantages children require. Such concerns taxed local, state, and national governments as reported by Mitchell, et al. 2015 and institutions such as UNESCO Global Monitoring and Bernard van Leer Foundation for which Fabian and Dunlop 2007 and Woodhead and Moss 2007 undertook reports. Here a selection of reports of such projects are included and illustrate global educational concerns about the effectiveness of pre-school and school and the transitions between them. A number of these reports contain helpful practical advice. Dockett and Perry 2014 includes a much recommended "Transitions to School Position Statement" (see *Research, Policy and Practices*) developed by an international research, policy, and practice group.

Dockett, Sue, and Bob Perry. 2014. *Continuity of learning: A resource to support effective transition to school and school age care[https://docs.education.gov.au/system/files/doc/other/pdf_with_bookmarking__continuity_of_learning-_30_october_2014_1_0.pdf]*. Canberra, ACT: Australian Government Department of Education. [class:report] 
This very accessible resource covers effective transition to school age care as well as the more documented transition to school. Rooted in the Australian system, these internationally regarded authors and their team build on a comprehensive knowledge of transitions research and policy and practice. Section 3 addresses principles and practice.

Education Review Office. 2015. *Continuity of learning: Transitions from early childhood services to schools[http://www.ero.govt.nz/assets/Uploads/ERO-Continuity-of-LearningFINAL.pdf]*. Tamaiti te Putake o te Kaupapa (The Child - the heart of the matter). An Educational Evaluation Report. Education Review Office, New Zealand. [class:report] New Zealand is one of the few countries that has undertaken a systematic governmental evaluation of early childhood to school transition process and practices. Two evaluation frameworks - for early childhood services (p. 57) and for schools (p. 64), are presented with "evaluation questions, investigative prompts and indicators." Users should interrogate the differences.

EU-Agency, Regional Government of Cologne/Germany, Project management. 2010. *Early Years Transition Programme (EASE): Transition from pre-school to school, emphasizing early literacy[http://www.ease-eu.com/documents/compendium/compendium.pdf]. OECD: Paris. [class:report]

This ambitious eight-country program considered a participatory approach to early literacy and language practice within the context of cooperation between early childhood and school sectors and with families. The project promotes sociocultural forms of assessment to support literacy transitions. Each of the twelve chapters can be read as a stand-alone.

Fabian, Hilary, and Aline-Wendy Dunlop. 2007. *Outcomes of good practice in transition processes for children entering primary school, Working Paper No.42 
[https://issuu.com/bernardvanleerfoundation/docs/outcomes_of_good_practice_in_transition_pro cesses_]*. The Hague, The Netherlands: Bernard van Leer Foundation (BVLF). [class:report] Originally commissioned as a background paper for UNECSO's Education for All Global Monitoring Report 2007, this publication is one of several on transitions issues produced by the BVLF (Numbers $41,42,48,55,56$ ). The authors advocate the co-construction of transitions processes by the different actors involved: families, children, and practitioners in community with each other.

Kagan, Sharon Lynn, and Elizabeth Rigby. 2003. *Improving the readiness of children for school: Recommendations for state policies[https://www.cssp.org/publications/publicpolicy/policy-matters-improving-the-readiness-of-children-for-school.pdf]*. Washington, DC: Center for the Study of Social Policy. [class:report]

School readiness is one of six core policy areas understood to have the most promise of making a difference to child and family well-being. Two constructs—-"ready to learn" and "ready for school"- are challenged. A multidimensional working definition of School Readiness is offered with four outcomes for policy evaluation.

Mitchell, Linda, Bronwen Cowie, Jeanette Clarkin-Phillips, et al. 2015. ${ }^{*}$ Continuity of early learning: Learning progress and outcomes in the early years. Overview Report on Data Findings[https://www.educationcounts.govt.nz/publications/ECE/continuity-of-early-learningdata-findings]*. Report commissioned by the Ministry of Education, New Zealand. [class:report] Assessment practices, individual learning outcomes, learning information valued by and shared with families and between early childhood services and school, are each understood to contribute to the continuity of experience offered to children. Reaching a shared understanding about types of assessment and their value for children's learning, knowledge, and agency matters. 
Peters, Sally, Vanessa Paki, and Keryn Davis. 2015. *Learning journeys from early childhood into

school[http://www.tlri.org.nz/sites/default/files/projects/TLRI_\%20Peters_Summary(v2)\%20(1). pdf]*. Teaching and Learning Research Initiative Report. [class:report]

The interpretative approach framed this study which gathered data from parents, children, and teachers, through interviews, observations, document analysis, teacher notes, and team meetings, in order to understand how children's learning journeys in transition to school are supported by their working theories, funds of knowledge, and dispositions, bringing sectors closer. Woodhead, Martin, and Peter Moss. 2007. *Early childhood and primary education. Transitions in the Lives of Young Children[http://oro.open.ac.uk/16667/1/ECiF2.DAT.pdf]. Milton Keynes, UK: The Open Univ. [class:report]

This report looks at evidence across the world to widen perspectives and ask new questions about transitions to school. Quality early childhood programs are potentially an effective bridge between home and school. Important policy questions are raised about partnerships, resources, expectations, communication, leadership, and the meeting of child rights.

\section{LITERATURE REVIEWS}

Literature Reviews of Transitions to School fall into three main categories: those commissioned by a government department, those commissioned by a research institute, and those commissioned by a foundation or other public body. There is usually a policy purpose in the commissioning of such reviews. Aside from these published reviews every $\mathrm{PhD}$ dissertation on transitions to school will have a well-researched literature section: these are usually lodged in university libraries and can provide access to the more immediate concerns of recently completed academic research. It is important when reading such reviews to be aware of the scope 
of the review, what the author was commissioned to do, and the inclusion and exclusion criteria employed for the work cited. In the field of transition to school research there would appear to be a gap in terms of systematic reviews of this growing area of research. Systematic review aims to identify, critically appraise, and summarize the evidence available, stating clearly what types of study have been included and the search criteria and sources used. Typically such review would limit the types of study deemed to be comparable in terms of sample, method, and analysis: some of the large-scale US transitions/population studies might fulfill such criteria and could extract transitions data at different time points, but many studies of educational transitions are much more eclectic. Such review is more common in health-based studies, and while behaviors at times of transition might be the subject of review, "Transitions in Early Childhood Education" does not appear in, for example, PROSPERO - the main international prospective register of systematic reviews. Notwithstanding, the reviews cited here offer a wealth of well-researched information organized in accessible ways and may be grouped into the three main categories: government departments (Hirst, et al. 2011 in Australia; Peters 2010 in New Zealand); those commissioned by a research institute (Centre for Equity and Innovation in Early Childhood 2008; McTurk, et al. 2008; Rosenkoetter, et al. 2009) and those commissioned by a foundation or other public body, for example, O’Kane 2016 (for the Irish National Council for Curriculum and Assessment) and Vogler, et al. 2008 (for the van Leer Foundation). Each provides considerable insight for practice, with strengths variously identified as insight into change, mutual perspectives, children's mental health and well-being, minority perspectives, curriculum alignment, parental and family partnerships, complexity, and a range of theoretical approaches. Centre for Equity and Innovation in Early Childhood (CEIEC). 2008. * Literature review transition: A positive start to 
school[www.education.vic.gov.au/Documents/about/research/transitionliteraturereview.docx]*. Victoria: Univ. of Melbourne. [class:book]

A modified best evidence synthesis (BES) which identified 125 relevant studies, and presents them in a useful at-a-glance table. Multiple perspectives are presented. Four dimensions emerge: definition of transition, changes needed and by whom, questions about evaluation evidence, the problematic concept of school readiness. Achieving mutual perspectives on transitions is aired. Hirst, Marie, Noni Jervis, Karen Visagie, Victor Sojo, and Sarah Cavanagh. 2011. *Transition to primary school: A review of the

literature[https://www.kidsmatter.edu.au/sites/default/files/public/Transition-to-Primary-SchoolA-literature-review.pdf]*. Canberra: Commonwealth of Australia. [class:book]

The Kids Matter suite of initiatives aims to develop greater parental engagement and confidence in their children's transition to primary school with the expressed purpose of supporting children's mental health and well-being. Focusing specifically on literature to support their own developments, the findings may be more widely applicable.

McTurk, Nick, Georgie Nutton, Tess Lea, Gary Robinson, and Jonathan Carapetis. 2008. The school readiness of Australian indigenous children: A review of the literature. Australia: Menzies School of Health Research and School for Social and Policy Research, Charles Darwin Univ. [class:book]

Minority perspectives are less evident in the transitions literature: in focusing on Australian aboriginal culture, this review invokes first nation experience globally: not unproblematic given the diversity of languages and culture. Here a holistic view is taken of ready schools, ready families, and ready communities as well as ready children. 
O’Kane, Mary. 2016. Transition from preschool to primary school: Research Report No. 19.

Dublin: National Council for Curriculum and Assessment. [class:book]

The purpose of this review is to inform policy development on the transfer of information between settings and the alignment of curriculum and pedagogy. It promotes an interactionist approach to the transition to school which links children's dispositions with the nature of relationships between settings and the adult participants involved.

Peters, Sally. 2010. Literature review: Transition from early childhood education to school. Wellington, New Zealand: Ministry of Education. [ISBN: 9780478342871] [class:book] Peter's work is included here as one of the most comprehensive, focused, and scholarly reviews of transitions literature in recent years. It makes clear that there are complexities and challenges for children in transition, but many learning opportunities too. Peters has also written the transitions section in the updated NZ Te Whariki Curriculum (2017).

Rosenkoetter, Sharon, Carol Schroeder, Beth Rous, Ann Hains, Jordan Shaw, and Katherine McCormick. 2009. A review of research in early childhood transition: Child and family studies. Technical Report \#5. Lexington: Univ. of Kentucky, Human Development Institute, National Early Childhood Transition Center. [class:book]

Child-focused and family-focused transitions form the two strands of this review which quantifies studies in terms of the volume of evidence and participant numbers: high-quality early learning and childcare settings are associated with good academic outcomes, as are close relationships between teachers and a good match of environments across sectors. Rosier, Kate, and Myfanwy McDonald. 2011. Promoting positive education and care transitions for children. Australia: Communities and Families Clearing House. [class:report] 
Key messages about transitions in early childhood are helpfully captured in this short resource sheet, which focuses on partnerships, parental and family circumstances, and the child's adaptation to school. The transition from home, between settings, and into school are addressed. Diversity, changes in identity, and prior experience are each recognized. Vogler, Pia, Gina Crivello, and Martin Woodhead. 2008. Early childhood transitions research: A review of concepts, theory, and practice. Working Papers in Early Child Development 48 . The Hague: Bernard van Leer Foundation. [ISBN: 9789061951032] [class:book] Recommended for readers who wish to engage with the variety of theoretical approaches to transitions: this review brings together notions of border crossing, cultural thresholds, developmental niche, ecological theory, guided participation, interpretive reproduction, sociocultural approaches, rites of passage, and life-course theory, offering some critique and advocating a holistic view.

\section{JOURNAL THEMED ISSUES, CHAPTERS, AND BOOK SERIES}

In this section what might be called "collections" of articles, chapters, and a book series are identified. One website hosting an online transitions journal is included here, but many journals carry articles on early childhood transitions. A current quick search reveals 216 articles in the European Early Childhood Education Research Journal, 190 articles in Early Years: An International Research Journal, 138 articles in Contemporary Issues in Early Childhood, and 180 articles in the International Journal of Early Years Education. It is clear that transitions in early childhood are a vibrant research interest. A taste of what is available is offered: all the work in this section has a strong international research base. One of the earliest collaborative publications was generated by the **European Early Childhood Education Research Association (EECERA) Transitions** Special Interest Group: through a strong shared interest the group 
elected to work on the first of EECERA's themed monographs, published in 2003 and simply titled Transitions. Kay Margetts has hosted and edited the online **Transitions in Early Childhood** journal since its inception: growing out of early meetings of the same EECERA Transitions Special Interest Group, it has afforded publication in an early childhood transitions focused journal at a time when no other journal is dedicated specifically to this field. From time to time peer-reviewed journals do run or invite contributions to special issues with such a focus_Early Years (Peters and Dunlop 2014) is such an example: only the editorial is cited here, but the issue includes a number of articles and innovative concepts, and similarly the New Zealand-based **Early Childhood Folio** was dedicated to transitions following a call for papers. The van Leer Foundation has also sustained an interest in early childhood transitions, beginning with commissioned work informing the global challenges the Education for All publications address, and illustrated by the inclusion of **Transitions in the Early Years: $A$ Learning Opportunity** and Woodhead and Moss 2007. Over the years there have been a number of dedicated early childhood transitions conferences: for example the Transforming Transitions International Conference at University of Strathclyde, Glasgow, in 2007, and **Petite Enfance: Socialisation et Transitions**, hosted in Paris and dedicated to petite enfance: meaning specifically the earliest provision for babies and under-threes. Many authors have contributed chapters to edited books, but one book series stands out: International Perspectives on Early Childhood Education and Development, edited by Marilyn Fleer and Ingrid PramlingSamuelsson, includes three edited volumes related specifically to transitions.

*Early Childhood Folio[http://www.nzcer.org.nz/nzcerpress/early-childhood-folio/earlychildhood-folio-vol-18-no-2-2014]*. 2014. 18.2. [class:journalArticle] 
A special issue focusing on transitions which includes articles from Australia, New Zealand, and Sweden, including a focus on communication between educators, transition portfolios, mapping transitions, parent decision making, transition to school, and teacher transitions.

Moreno, Teresa, and Jan van Dongen, eds. 2006. Special issue: Transitions in the early years: A learning opportunity. Early Years Matters Journal 107. [class: JournalArticle]

Reflecting international perspectives, this journal issue argues for a more positive view to foster home-school links, work with under-threes, and community participation. Transitions are defined as "thresholds" and a rights-based framework is invoked with five themes: peers and priming; intergenerational support; curriculum and pedagogy; children's agency and leadership; and partnership.

The European Early Childhood Education Research Association (EECERA) Transitions. 2003. European Early Childhood Education Research Journal.

The Transitions Special Interest Group (SIG) meets at the Annual EECERA Conference to share research interests, publications, and projects. The SIG proposed a peer-reviewed themed monograph on transitions: articles published reflected transitions issues including agency, resilience, social competence, and frameworks for learning across Europe, Singapore, New Zealand, and Australia.

*International Perspectives on Early Childhood Education and Development[http://www.springer.com/series/7601]*. [class:bookSeries] Three edited volumes comprising in total fifty-four chapters relating to different aspects of early childhood transitions: Volume 9: Transitions to School-International Research, Policy and Practice, edited by Bob Perry, Sue Dockett, and Ann Petriwskyj (2014); Volume 16: Pedagogies of Educational Transitions: European and Antipodean Research, edited by Nadine Ballam Bob 
Perry and Anders Garpelin (2017); Volume 21: Families and Transitions to School, edited by Sue Dockett, Wilfried Griebel, and Bob Perry (2017).

Peters, Sally, and Aline-Wendy Dunlop. 2014. Editorial. Early Years 34.4: 323-328.

[doi:10.1080/09575146.2014.982903] [class:journalArticle]

The range of transitions topics covered in this special issue journal is summarized in the guest editorial and includes special needs, parental advocacy, transitions within an early childhood setting, and seven papers on early childhood transitions. Voice, communication between interested parties, professional collaboration, and a concept of boundary spaces are informative. *Petite Enfance: Socialisation et Transitions (Early Childhood: Socialization and Transitions)[https://hal-univ-paris13.archives-ouvertes.fr/PETITE-ENFANCE]*. 2015. [class:webLink]

See the tab "Consulter les dépôts." Reflecting work from a dozen countries, this conference on transitions for very young children recognized that existing published work on transitions in the early years is often school-start related. The proceedings presented online introduce a range of work with babies and very young children and their socialization in transition processes.

*Transitions in Early

Childhood[https://extranet.education.unimelb.edu.au/LED/tec/index.shtml]*. Univ. of Melbourne, Australia. [class:webLink]

Kay Margetts, associate professor at the University of Melbourne, has hosted this website and the Transitions in Early Childhood Journal over fifteen years: articles from Australia, England, Denmark, Germany, Finland, New Zealand, Poland, Sweden, Iceland, Norway, Scotland, and Wales reflect the international interest and diversity of work in transitions across the world. 
Woodhead, Martin, and Peter Moss. 2007. Early childhood and primary education: Transitions in the lives of young children. Early Childhood in Focus 2. The Hague: Bernard van Leer Foundation. [ISBN: 9780749212742] [class:book]

This second volume in the series deals with the global challenges of education for all, especially for the youngest children: implications of growth in early childhood education and care, including a reappraisal of traditional concepts of school readiness, and a review of strategies required to ensure continuity in children's experiences of successful transitions.

\section{TOPICAL ISSUES}

This section presents a range of topical issues in early childhood transitions research and publication, each of which raises its own set of ethical issues in the conduct of research. The section therefore begins with the recognition that an increasing number of such research projects seek a range of perspectives and there is a strong focus on multiple voices of the various people and interests involved at times of transition. The need to respect and understand the ways in which participation in early childhood transitions research positions participants is core to the selection of topics and works cited in the following topic sections. This must raise issues of how consent and assent are understood and the right of any potential participant to refuse to participate in research. To what extent is what we have collectively learned from "listening" (a term that describes more than the physical act of listening itself and is active not passive) to children ready to be put into practice? This surely is the purpose of accessing children's views: so that this translates into responsive practices. Throughout the **Topical Issues** sections readers will find ample implications for, and examples of, transitions practices. 


\section{Ethical Encounters in Transitions to School Research with Children}

There is a strong focus on voice and perspective of the child that raises particular issues of what is meant by consent and assent and the right of any potential participant to refuse to participate in research with children in mind. In attempting to map young children's perspectives on early childhood transitions, including transitions to school, it is important to consider the variety of approaches described by Alison Clark when she asserts that "Research and practice which takes seriously children's perspectives on their everyday lives has become an important element of childhood studies" (Clark 2005, p. 490). Research methods and methodology must always be chosen with the potential impact of those approaches upon the child participant in mind. Harcourt and Einarsdóttir 2011 asserts that in researching with children, their influence on the research design must be included and respected. The capacity to create culture and to energize rich learning in the companionship of others that Trevarthen 2012 proposes has potential to influence research design too. Alderson and Morrow 2011 offers a benchmark upon which the ethics of research work with children may be developed. There is a mix of theoretical approaches across the work of Clark 2005, Dockett and Perry 2011, and Harcourt and Einarsdóttir 2011; practical examples provided by Einarsdóttir 2014; richly researched single topic publications such as Brooker 2002 (work on the school start of Bangladeshi children living in London); articles illustrated by research evidence such as Harcourt, et al. 2011; and the philosophical underpinnings of long-experienced researchers such as Trevarthen 2012. Each of these works complement one another other in a strong account of what matters in research with children, with many illustrations from transitions work.

Alderson, Priscilla, and Virginia Morrow. 2011. The ethics of research with children and young

people: A practical handbook. 2d ed. London: SAGE. [ISBN: 9781446209387] [class:book] 
This foundational work on the ethics of research with children and young people is included here as work on transitions for and with children raises ethical issues: this text supports researchers to recognize, think about, and address such issues. Though not a text about transitions, two transitions examples are included.

Brooker, Liz. 2002. Starting school: Young children learning cultures. Buckingham, UK: Open Univ. Press. [ISBN: 9780335209323] [class:book]

This award-winning work framed the huge shifts in culture for Bangladeshi children living in London as they moved between home, preschool, and school. Understanding of such change on an intimate individual as well as cultural level is shown by using Bourdieu's concepts of field, habitus, and social and human capital.

Clark, Alison. 2005. Listening to and involving young children: a review of research and practice. Early Child Development and Care 175.6: 489-505.

[https://doi.org/10.1080/03004430500131288] [class:journalArticle]

It is important to be aware of our own perspectives on children and childhood. Today the children's rights discourse and sociology of childhood influence educational perspectives. The transitions field attempts to understand and reflect children's perspectives: listening effectively to children is central to this endeavor.

Dockett, Sue, and Bob Perry. 2011. Researching with young children: Seeking assent. Child Indicators Research 4:231-247. [class:journalArticle]

Making important points about the agency of children in research, the authors distinguish between the consent of adults and a relational model of assent involving children, based on a continuing negotiated process throughout a study. This article is an informative addition to the ethics literature from two experienced transitions researchers. 
Einarsdóttir, Johanna. 2014. *Children's perspectives on moving from preschool to primary school[https://bernardvanleer.org/app/uploads/2016/04/Steps-for-Engaging-Young-Children-inResearch-Volume-1-The-Guide0b91.pdf]*. In Steps to engaging young children in research. Volume 1: The guide. Edited by V. Johnson, R. Hart, and J. Colwell, 98-100. Brighton, UK: Univ. of Brighton, Bernard van Leer. [class:bookChapter] This is one volume from Van Leer on engaging children in research. It is a joyful practical guide in which this article is but one example of research processes. Power relations are headed up as a critical issue in ensuring there is no coercion, however subtle, upon children to participate. Harcourt, Deborah, and Johanna Einarsdóttir. 2011. Editorial: Introducing children’s perspectives and participation in research. European Early Childhood Education Research Journal 19.3: 301-307. [class:journalArticle]

In this special issue, the challenges and assumptions about learning from children are recognized as carrying tensions. Attention to agency, rights, spaces for engagement, and relational aspects of understanding perspectives foreground the ethical issues inherent in this field and introduce an important set of articles with two evidencing transitions perspectives.

Harcourt, Deborah, Bob Perry, and Tim Waller, eds. 2011. Researching young children's perspectives: Debating the ethics and dilemmas of educational research with children. London: Routledge. [ISBN: 9780415604949] [class:book]

The principles and practices of research with children are addressed through a rights-based approach. This book is included as an important background to ethical approaches to research in which several chapters either focus on transitions issues in early childhood (e.g., "hearing school beginners"), or are contributed by known transitions researchers. 
Trevarthen, Colwyn. 2012. Finding a place with meaning in a busy human world: How does the story begin, and who helps? Editorial. European Early Childhood Education Research Journal 20.3: 303-312. [doi:10.1080/1350293X.2012.704757] [class:journalArticle] Writing about respecting children's "lived engagement" and "zest for learning," Trevarthen advocates the recognition of "human sense" in children's meaning-making in companionship with others. His knowledge and principles must exert a strong influence on the ethics of encounters with children as whole and "reasonable" persons. An essential reading.

\section{Children's Perspectives, Agency, Advocacy, and Voice}

There is a continuing methodological challenge in understanding young children's perspectives on the transition to school. Considering children's perspectives means reflecting, as Dunlop 2003 and Lam and Pollard 2006 highlight, on their agency. Mason and Danby 2011 emphasizes voice, while Peters, et al. 2015 reminds us of the ways in which others may advocate for children. How do researchers, practitioners, and policymakers form views, vistas, opinions, a vision, a mental outlook, or a particular "take on things? Some of the elements that come to mind are through watching, listening, reading, imagining, and asking others, and also through first-hand experience. Time also becomes a factor in reflecting upon perspectives-looking back and recalling and experiencing now in the moment may be more accessible than prediction or imagination of an unknown: this becomes an issue in research with children. Given the number of researchers considering children's perspectives on transition—often the transition to schoolis it really possible to seek the child's point of view? Children may walk us through, talk us through, as Loizou 2011 points out, symbolize through drawings and maybe photographs. In examining children's perspectives do we intend to take the next step and consider how their perceptions could be used to inform transitions processes? Transforming learning environments, 
improving relationships, valuing the resources children value, each makes us think about teacher role, as Margetts 2013 suggests, in respecting what children are able to do. In her 2009 editorial Penny Munn (Munn 2009) refers to Esme Hall's argument on the role that drawing has in ordering children's perceptions, actions, and understanding of their world and how this has taken second place in curriculum to aspects of literacy skills. Munn argues for contextualized analysis of children's drawings, thereby minimizing adult assumptions, and "prioritises children's perceptions of their drawings and the motivations and intentions lying behind any particular drawing" (p. 177). In working with children to allow their views to surface we need to ask what we are tapping into - might it be the changes as children make the transition to school? Or could it be their knowledge of difference? Perhaps we are simply extrapolating from what we observe: these papers illustrate a range of approaches to finding children's patterns of interest, experience, and concerns at times of transition in which each aims to recognize the diversity of children and their voices—and therefore of their thinking, their changing identities Ackesjö 2013 and to recognize and address the balance of power between children and adults in both research and practice as so strongly evidenced by McNair 2016. The selected papers in this section address these issues.

Ackesjö, Helena. 2013. Transitions - times of reconstructions. International Journal of Transition in Childhood 6:16-27. [class:journalArticle]

Embracing the importance of children's perspectives, Ackesjö sheds light on children's participation in different contexts, by considering identities and borders as interwoven. The degree to which children exercise agency in the identity reconstructions that occur for them in transition show the extent to which they feel they have meaning in new situations. 
Dunlop, Aline-Wendy. 2003. Bridging early educational transitions in learning through children's agency. European Early Childhood Education Research Monograph, ser. 1: 67-86. [class:journalArticle]

This paper argues that to understand children's sense of agency and the extent of their power to act, we must obtain a deep understanding of playroom and classroom discourse: it is through relationships and communication that the balance of power and control becomes visible and sheds light on transition mismatches.

Lam, Mei Seung, and Andrew Pollard. 2006. A conceptual framework for understanding children as agents in the transition from home to kindergarten. Early Years 26.2: 123-141. [class:journalArticle]

This conceptual framework positions children as strategic agents in their adaptation to changes in status and context in the transition from home to kindergarten. The framework builds on Pollard's work on "pupil career" and frames transitions drawing from van Gennep's "rites of passage": critiquing and providing answers to some weaknesses (1960). Loizou, Eleni. 2011. Empowering aspects of transition from kindergarten to first grade through children's voices. Early Years 31.1: 43-55. [class:journalArticle] Loizou's work takes an empowerment perspective on engaging with children to influence transitions in early childhood through conversational interviews focusing on the reflective comments of a sample of fifty-five first-grade children in Cyprus. Enabling and limiting experiences are drawn out: space and time are needed for children to voice their empowerment. Margetts, Kay. 2013. What new children need to know: Children's perspectives of starting school. In International perspectives on transitions to school: Reconceptualising beliefs, policy 
and practice. Edited by Kay Margetts and Anna Kienig, pp. 79-97. London and New York: Routledge. [ISBN: 9780415536127] [class:bookChapter]

This chapter underlines what new children entering school need to know from the perspective of children who have already made that transition. The validity of their suggestions of help with relationships, rules, and procedures, as well as academic skills and knowledge, justifies action by educators on each side of transition.

Mason, Jan, and Susan Danby. 2011. Children as experts in their own lives: Child inclusive research. Child Indicators Research 4:185-189. [class:journalArticle]

This article raises questions about research that understands children's lives as less-experienced to more-experienced trajectories, instead proposing that valuing children's agency and voice means that understanding life in the here and now makes an important contribution. This shift is particularly important for transitions researchers and practitioners who work with both perspectives.

McNair, Lynn J. 2016. "Rules, rules, rules and we're not allowed to skip": Exploratory study: Listening to young children's voices about the transition to Primary One. PhD diss., Univ. of Edinburgh. [class:thesis-phd]

This abductive ethnographic study presents high-quality new work exploring children's perspectives on transition to school. Using Gore's analytics of power: surveillance, normalization, exclusion, classification, distribution, individualization, totalization, and regulation, the author illustrates each of these concepts with children's voices and concludes that issues of power are under-researched in transitions (1995).

Munn, Penny. 2009. Professional development and understanding children's perspectives. (Editorial). International Journal of Early Years Education 17.3: 177-178. [class:journalArticle] 
This short editorial is included as a lead into the important articles in this issue, which links practitioner skill and reflection with a capacity to understand and enable action based on children's perspectives. Engaging with children's perceptions is a complex task for early years professionals and merits continuing development.

Peters, Sally, Vanessa Paki, and Keryn Davis. 2015. Learning journeys from early childhood into school. Summary Report. New Zealand: Teaching and Learning Initiative. [class:report] Looking at what makes for successful transition between early childhood and school, this project specifically set out to improve that experience for Maori children. A set of helpful cultural indicators are included (pp. 18-20). The building of strong relationships was found to be a key factor, as were contextual solutions.

\section{Family Engagement (Parental and Family Transitions)}

The transition to school is no longer the first transition small children make but is nevertheless a significant one. Any transition for the child, any transition for the family, is a transition for both. Fthenakis 1998 was an early highlight of changing trends in family composition and situations; the author recognizes all bring transition in role and identity. Much has been written about the impact of family involvement in their children's education. In the transitions literature there is a growing emphasis on going beyond the giving of information to parents in order to consider how parents are positioned by the education system and to co-constructing their children's transitions collaboratively as illustrated by Wildgruber, et al. 2011. Parents' perspectives are bound to be influential for children, however, although many studies find a relationship between parental involvement and later school success. Gorard and Beng Huat See's report for the Nuffield Foundation queries a causal relationship between parental involvement and school success (2013). They question gaps and quality in research, but does not consider transitions so is not 
central to the present article: this review is, however, representative of a growing trend among public bodies that only randomised controlled trials (RCTs) will stand up to scrutiny. Jovés, et al. 2015 shows us that if qualitative work is to be valued this will mean working closely with families to understand better the skills, knowledge, and achievements of children and their families as a bridge to school: their "funds of knowledge" approach is very promising. In the family engagement arena too, there is still a "hard-to-reach, hard-to-engage" rhetoric that professionals interested in early childhood transitions may need to challenge. Sayers, et al. 2012 confirms that it is important to probe deeply the measurement of domains of children's development, in order to have what are referred to as "process and impact indicators" (p. 45) given, for example, the critical literature on Australian Early Development Index (AEDI) is practically non-existent and asserts that the information gathered will help practitioners to serve certain communities better. By contrast Dockett, et al. 2017 looks at how learning is organized across a range of cultures, allowing a much more positive view to surface. As Sue Dockett says in the closing chapter: "The building of partnerships - or collaborations - between families and educators at the time of transition to school is regarded as an essential element in the provision of high quality education" (p. 261). The work of Cottle and Alexander 2014; Potter, et al. 2012; and Shields 2009 each have much to share about whether such collaboration attempts work. Cottle, Michelle, and Elise Alexander. 2014. Parent partnership and "quality" early years services: Practitioners' perspectives. European Early Childhood Education Research Journal 22.5: 637-659. [https://doi.org/10.1080/1350293X.2013.788314] [class:journalArticle] A thoughtful debate about types of parental contact and the ways in which the state, in promoting parental involvement/participation as a measure of quality, has changed the nature of 
relationships. One of the expressed purposes of this movement in England is to help parents and children navigate transitions positively.

Dockett, Sue, Wilfried Griebel, and Bob Perry, eds. 2017. Families and transition to school. Cham, Switzerland: Springer International. [ISBN: 9783319583273] [class:book]

This edited collection brings together an international group of writers to address the ways in which families and their children navigate the transition to school: consequently many issues surface - additional needs, families with refugee status, intergenerational supports, and the shared or contested narratives of parents and educators leading to transitions and transformations.

Fthenakis, Wassilios. 1998. Family transitions and quality in early childhood education. European Early Childhood Education Research Journal 6.1: 5-17.

[https://doi.org/10.1080/13502939885208131] [class:journalArticle]

This much-cited seminal article laid a foundation for taking a family perspective on transitions and urges educators to respond to contextual factors as children navigate new kinds of discontinuities and an increasing volume of transitions in their lives, though impacts of poverty, divorce, parenthood, mobility, and changing views of childhood.

Jovés, Pol, Carina Siqués, and Moisès Esteban-Guitart. 2015. The incorporation of funds of knowledge and funds of identity of students and their families into educational practice. A case study from Catalonia, Spain. Teaching and Teacher Education 49:68-77. [class:journalArticle] A mismatch of cultural values and behaviors of home and community for poorer and minority children may bring about home-school discontinuity and cause more problematic transitions between home and school expectations. A novel approach of linking funds of knowledge and funds of identity offers an important application for early childhood. 
Potter, Carol, Gary Walker, and Bev Keen. 2012. Engaging fathers from disadvantaged areas in children's early educational transitions: A UK perspective. Journal of Early Childhood Research 10.2: 209-225. [class:journalArticle]

Imperatives for father engagement in their children's education have grown as research increasingly shows the longer-term benefits, while illustrating the challenges of feminized early childhood settings and early primary practices. This study focuses on father involvement in the transition from early years to mainstream school. A gendered approach brought successes. Sayers, Mary, Sue West, Jen Lorains, Bella Laidlaw, and Rachel Robinson. 2012. Starting school: A pivotal life transition for children and their families. Family Matters 90:45-56. [class:journalArticle]

The AEDI (Australian Early Development Index) identified significant numbers of "developmentally vulnerable" and "additional needs" children arriving in school. Aiming to develop a more useful measure of the transition to school process and outcomes, the authors present outcomes of a positive start and promising practices for a strengths-based approach to school start.

Shields, Polly. 2009. "School doesn't feel as much of a partnership": Parents' perceptions of their children's transition from nursery school to reception class. Early Years 29.3: 237-248. [class:journalArticle]

The tradition of strong and positive parent-educator relationships in early childhood settings contrasts with a felt lack of partnership, in this English study, once children have made the transition to school. An intimate case-study approach shows how it is for parents when they feel excluded from their child's school day. 
Wildgruber, Andreas, Wilfried Griebel, Renate Niesel, and Bernhard Nagel. 2011. *Parents in their transition towards school. An empirical study in

Germany[https://extranet.education.unimelb.edu.au/LED/tec/pdf/wildgruber1.pdf]*. Paper presented at the 21st European Early Childhood Education Research Association Annual Conference "Education from Birth: Research, Practices and Educational policy," Geneva, 14-17 September 2011. Munich: State Institute of Early Childhood Research (IPF). [class:conferencepaper]

This research grouping has produced a number of English- and German-language papers over a period of years, including a range of work on family and parent perspectives from a family developmental psychology theoretical base. Rich insights into cooperation between early childhood settings, schools, and families in transition are presented.

\section{Diversity and Inclusion in Transitions to School}

The main focus in early childhood transitions has been the transition to school. Other transitions are less researched - transitions within the family, transition into the first out-of-home setting which may be a baby-room or a toddler group; the repeated transitions children make across the day or adjusting to family changes. Another set of perspectives represented in research on early transitions are the experiences of different segments of the child population. These include Arndt, et al. 2013 and Crosnoe and Cooper 2010, discussions of different socioeconomic groups; D'Arcy 2012 on different ethnicities; and Dockett, et al. 2011 and Sammons, et al. 2003 in their reports on children with additional support needs. The language of such articles is also shifting, exemplified by Dockett and colleagues' use of the term "complex support needs." Often families and their children are affected by multiple challenges, and this is reflected in Entwisle, et al. 2007, which attends to the combination of gender and poverty that places many boys at 
educational disadvantage, something that is increasingly recognized in contemporary policy initiatives. Less common is a focus on Armed Forces children — a large group under-represented in the literature, who experience many transitions and have much insight to share as Fabian and Roberts 2011 shows. A growing group experiencing multiple transitions that remains seriously underrepresented in the literature are the children of migrant, refugee, and asylum-seeking families. In this section we include a sample of this diversity with the article Turunen and Perry 2013 on the stories of immigrant adults as insight into justices and injustices that are still pervasive. Here we focus on transitions to school articles, but further citations on different aspects of transition appear in other sections.

Arndt, Ann-Kathrin, Antje Rothe, Michael Urban, and Rolf Werning. 2013. Supporting and stimulating the learning of socioeconomically disadvantaged children - perspectives of parents and educators in the transition from preschool to primary school. European Early Childhood Education Research Journal 21.1: 23-38. [class:journalArticle] The reported pre-school phase of a longitudinal study finds that educators are negative about the learning contributions of socioeconomically disadvantaged families. Positioning such families in deficit-mode exerts power-relations in which educators offer advice and are deemed to have a superior knowledge about learning, which is exacerbated by their welfare monitoring function. Crosnoe, Robert, and Carey E. Cooper. 2010. Economically disadvantaged children's transitions into elementary school: Linking family processes, school contexts, and educational policy. American Educational Research Journal 47.2: 258-291. [class:journalArticle] Often associated with disadvantage, in cyclical intergenerational disadvantage, longer term childfocused approaches are needed to improve children's future prospects. Extending a family socialization model to include children's social and emotional adjustment on transition to 
elementary school. Teachers experienced in working at entry stage provided a buffer against low reading results.

D’Arcy, Kate. 2012. How can early years services improve access and transition into early years settings and primary schools for Gypsy, Roma and Traveller children? Leeds, UK:

Children's Workforce Development Council. [class:book]

A practitioner-led project, four approaches emerged: interagency working; professional development; training and support, and sustainability. Practitioners felt better informed, more confident and more reflective about supporting access and transitions. Issues of trust were raised by families, who had been fearful of racism and prejudice. New strategies were developed. Dockett, Sue, Bob Perry, Emma Kearney, Anne Hampshire, Jan Mason, and Virginia Schmied. 2011. Facilitating children's transition to school from families with complex support needs. Albury, Australia: Research Institute for Professional Practice, Learning and Education, Charles Sturt Univ. [ISBN: 9781864672305] [class:book]

The title of this interesting report challenges the stereotyping often associated with disadvantage and disability. It advocates a strength-based approach to transitions, which are embraced as opportunities. Parental aspirations are identified and strategies and supports considered as enabling practices, enabling processes, and enabling policies that respect families.

Entwisle, Doris R., Karl L. Alexander, and Linda S. Olson. 2007. Early schooling: The handicap of being poor and male. Sociology of Education 80.2 (April): 114-138. [class:journalArticle] This longitudinal study highlights how parents and teachers treat boys in early childhood settings, at transition, and in elementary school. Reading is considered pivotal, and early years an opportunity: classroom behavior, parental expectation, reading marks, and retention predict 
higher reading achievement for girls. Gender and SES predict educational attainment at age twenty-two.

Fabian, Hilary, and Carl Roberts. 2011. Children in transition: Learning to become global citizens In Global Migration and Education: Schools, Children and Families. Edited by Leah D. Adams and Anna Kirova, 279-292. London and New York: Routledge. [class:bookChapter] Another group that experiences frequent educational transitions are forces children. This study explores levels of social and emotional well-being surrounding transitions, ways in which children achieve strategies for dealing with change and curriculum continuity. Exerting agency and developing resilience is helped by moving with friends and with advance information about the next school.

Sammons, Pam, Brenda Taggart, Rebecca Smees, et al. 2003. The Early Years Transition \& Special Educational Needs (EYTSEN) Project. Effective Pre School, Primary \& Secondary Education (EPPSE), Research report (Great Britain. Department for Education). [class:report] This report provides important contribution to the knowledge base on transitions and progress for "at risk" children, linking this status to multiple disadvantage and home learning environment. Preschool attendance at high-quality settings mitigates risk to some extent, particularly in cognitive and socio-behavioral domains. Parental perceptions of support are included.

Turunen, Tuija A., and Bob Perry. 2013. Immigrant background Australians' recollections of justice, injustice and agency in stories about starting school. Contemporary Issues in Early Childhood 14.4: 335-344. [class:journalArticle] Gathers early educational transitions stories from immigrant adults, reflections on agency, adaptation, meshing of different cultures, and resistance surface. The concepts of justice and injustice shed an important light on how language and food represent culture, cause 
embarrassment, and require sensitive support through teachers and peers. Valuing diversity matters.

\section{Professional Responses (Collaboration, Communication, and Continuity)}

The perspectives of educators in early childhood and early school settings are well represented in the literature on transitions to school. Differences in culture between home and school and preschool and school mean that professionals must take careful account of the relational approaches they develop so they can maximize their responses to children, families, and the communities in which they work. Like Corsaro and Molinari (cited under *Identity as a School Child, Peer Play and Peer Relations* and *Research, Policy and Practices*), Garpelin, et al. 2010 identifies individual and collective cultures and processes that are developed by children and fostered by practitioners during transitions. A range of issues surface for early educators either side of the transition to school: a chapter of OECD Starting Strong V 2017 is devoted to professional continuity. In discussions reported in these articles, there seem to be a lot of similarities expressed by practitioners in both sectors: they speak of children's independence and choice, of passing on information and building on what children already know, and they invoke a range of strategies which may include visits between sectors, passing on documentation, involving parents and children, starting school with peers. In translation these words and phrases do not necessarily mean the same thing and, as evidenced in other sections, the perspectives of educators do not always coincide across sectors, nor with other stakeholders such as parents. Thus it becomes clear that strategies and approaches are needed to support collaboration, illustrated through different means in both Peters, et al. 2012 and Pianta and Kraft-Sayre 2002. Sarja, et al. 2012 clearly acknowledges differing cultures while Vrinioti, et al. 2010 contributes to the debate on equipping children with appropriate literacy skills across the transition. 
Developing mutual views with other stakeholders remains a challenge around times of transition as both Hopps 2014 and Boyle and Petriwskyj 2014 show: all of these contributions emphasize that relationships are fundamental, and as Hogsnes 2015 affirms, that dialogue is central.

Boyle, Tess, and Anne Petriwskyj. 2014. Transitions to school: Reframing professional relationships. Early Years 34.4: 392-404. [class:journalArticle]

This scholarly article unpacks the importance of cross-sectoral relationships between professionals in terms of "functional linkages, systemic linkages, partnership interactions and dialogic interactions" (p. 393). This participatory action research found that relationships frame the possibilities for continuity and may change through dialogic interaction when space can be made for such engagement.

Garpelin, Anders, Pernilla Kallberg, Kenneth Ekström, and Gunilla Sandberg. 2010. How to organise transitions between units in preschool. Does it matter? International Journal of Transitions in Childhood 4:4-12. [class:journalArticle]

Seeing transitions as an integral part of pedagogy means recognizing rites of passage as children move between units in preschool. Teacher perspectives are influential and can position children as individuals or part of collective change. In either case there is scope for teacher development and reflection on what their approach achieves.

Hogsnes, Hilde D. 2015. Children's experiences of continuity in the transition from kindergarten to school: The potential of reliance on picture books as boundary objects. International Journal of Transitions in Childhood 8:3-13. [class:journalArticle]

Hognes contributes to the discourse of continuity by proposing the use of boundary objects, a concept drawn from cultural-historical activity theory: here in the form of picture books through 
which children can experience and influence for common elements between settings as they transition. This familiarity provides continuity and a sense of place.

Hopps, Kathryn. 2014. Communication that supports positive relationships between preschool and schools at the time of children's transitions. Early Childhood Folio 18.2: 8-14.

[class:journalArticle]

Relationships between children's preschool and school educators are regarded as an important influence on children's transition to school. This article reports on a study which investigated the nature of communication between preschools and schools in Australia. The strengths and weaknesses of communication reported by educators indicate elements which build positive relationships between settings, and those elements that strain relationships.

OECD. 2017. Starting strong V: Transitions from early childhood education and care to primary education. Paris: OECD. [class:book] OECD countries face three main challenges in fostering professional continuity to support children's transitions: these are discrepancies in status and perspectives between ECEC and primary school staff, lack of relevant training in transitions, and structural hurdles to cooperation and coordination. A lengthy chapter, the emphasis is on smooth, well-managed transitions. Peters, Sally, Margaret Carr, Carol Hartley, Pat Rogers, and Jemma Smith. 2012. Crossing the border: A community negotiates the transition from early childhood to primary school. Wellington, New Zealand: CER Press. [ISBN: 9781927151471] [class:book] In New Zealand conversations about the alignment of curriculum and pedagogy cross sectors in early childhood and school are ongoing. Crossing the Border gives an in-depth account and analysis of how cooperation and shared working can be achieved in the best interests of children making the transition to school. 
Pianta, Robert C., and Marcia Kraft-Sayre. 2002. Successful kindergarten transition. Baltimore: Paul Brookes. [ISBN: 9781557666154] [class:book]

Recognizing that every family's transition needs are different, this research-based practical guide for transition planning suggests three features - collaboration and relationships; adopting a shared conceptual model of transitions, and responding locally to community. Administrative leadership is important, but mutual trust and willingness to be flexible matter for transition outcomes.

Sarja, Anneli, Pirjo-Liisa Poikonen, and Monica Nilsson. 2012. Interprofessional collaboration in supporting transition to school: In Transitions and transformations in learning and education. Edited by Päivi Tynjälä, Marja-Leena Stenström, and Marjatta Saarnivaara, 87-101. Dordrecht, The Netherlands: Springer. [ISBN: 9789400723115] [class:bookChapter] Addressing the lack of continuity in early education on the system level, this chapter acknowledges differing early childhood cultures and procedures. It considers dialogue, sharing know-how, and creating knowledge as important ingredients in activity theory to develop shared work and bring about change to a more child-centered approach to transitions.

Vrinioti, Kalliope, Johanna Einarsdóttir, and Stig Broström. 2010. Transitions from preschool to primary school. In Transition from pre-school to school: Emphasizing early literacy. Comments and reflections by researchers from eight European countries. Edited by H. Müller, 16-20. Cologne, Germany: EU-Agency, Regional Government of Cologne. [class:bookChapter] One of the imperatives in educational policy internationally is equipping children with the tools for education: literacy is a priority globally, transitions have become so. This chapter is included in Müller's book to set the context of what professionals, parents, and children face in the transition to school within an ecological framework. 


\section{Children as Learners: Engaging with Curriculum}

The earliest work on transitions in early childhood focused principally upon pastoral (social, emotional) and the physical nature of transition from location to location. Much less focus was given to the transitions children were making as learners. Thirty years ago the work of Alexander and Entwistle 1998 marked a shift in what was valued in transitions research: it may be argued that such work brought a new focus to looking at continuity or discontinuity of learning experience already being studied by McCail 1996, which heralded the introduction of early childhood curricula in many countries worldwide. Dunlop's initial reporting of data from her longitudinal study of transitions drew on a concept of continuity and progression in children's learning and led to Dunlop 2002, her article on "Children as Learners in the Transition to School." The question of stability and change in environments in the transition from kindergarten to first grade is addressed by La Paro, et al. 2006. One of the most challenging debates in the field of transitions research, policy, and practice is the status of early childhood as a phase to be valued in its own right, free from the notion of preparation for the next stage: Fisher 2009 emphasizes the shift in children's views of themselves as learners when initiatives such as the English Literacy Strategy change the responsive pedagogies values in early childhood. Such thinking argues that it is incumbent on any following phase of care or education to be ready for all children: this rests on a recognition of the diversity and differences between children, their home situations, their family or community's economic, cultural and language status: a repeat of first grade heralds failure later in education (Allen 2017). Such high-risk populations may benefit from the assessment approaches presented by McDermott, et al. 2013. As governments seek more accountability in relation to the investment in early childhood, the gains in cognitive outcomes of early childhood programs have come under more scrutiny. There is discussion of 
curricular alignment, guidance now frequently includes a section on transitions, and a few countries have adopted a "through" curriculum (3-18. 0-12) in an attempt to reduce gaps between pedagogies and opportunities in different sectors of education. The warmth of relationships, as identified by Spilt, et al. 2015 , can only be helpful to young learners. Alexander, Karl L., and Doris R. Entwisle. 1998. Achievement in the first 2 years of school: Patterns and processes. Monographs of the Society for Research in Child Development 53.2: 1157. [class:journalArticle]

This rich and thorough monograph shows the value of longitudinal studies of transition. Taking a sociological as well as a psychological frame, the authors recognize further understanding of school-effects is needed in the study of transitions. A focus on changes in cognitive achievement over different time-points is well realized.

Allen, LaRue. 2017. *Transitions to school: What helps children succeed? Essentials for success in preschool and beyond[http://www.apa.org/about/gr/issues/education/pallen.aspx]*. American Psychological Association. [class:journalArticle]

This is one of the few publications that mentions children being ready for the transition, rather than ready for school. The stark fact that children who repeat first grade are the children most likely to drop out of school captures the importance of getting the transition right for each child. Dunlop, Aline-Wendy. 2002. Perspectives on children as learners in the transition to school. In Transitions in the early years: Debating continuity and progression for children in early education. Edited by Hilary Fabian and Aline-Wendy Dunlop, 98-110. London: Routledge Falmer. [ISBN: 9780415276399] [class:bookChapter] Abiding transitions themes are discussed: differing models of children between sectors, single or continuous curricula, educators', parents', and children's own perceptions of themselves as 
learners, and whether learning makes "human sense" for young children. Shared conceptual frameworks and meeting places that respect difference but move toward a mutual view are required.

Fisher, Julie A. 2009. "We used to play in Foundation, it was more funner": Investigating feelings about transition from Foundation Stage to Year 1. Early Years 29.2: 131-145. [class:journalArticle] Teachers, parents, and children were consulted about moving on to Year 1: there are marked differences including in pedagogy and assessment. Boredom, lack of play, and the constraints imposed by the current literacy strategy all meant that children had to adjust quickly to a new view of themselves as learners.

La Paro, Karen M., Sara E. Rimm-Kaufman, and Robert C. Pianta. 2006. Kindergarten to 1st grade: Classroom characteristics and the stability and change of children's classroom experiences. Journal of Research in Childhood Education 21.2: 189-202. [https://doi.org/10.1080/02568540609594588] [class:journalArticle] To date there had been little research looking at patterns of classroom experiences on either side of transition. Observational data drew out teaching activities, learning formats, and children's engagement as well as teacher qualities and pedagogy. It was found that instructional support decreased in quality with transition: a negative discontinuity. McCail, G. 1996. Curriculum continuity between Lothian nursery and early school education. Archived Interim Research Report. Edinburgh: Moray House Institute of Education, Heriot Watt Univ. [class:book] An ethnographic case study approach designed to explore in depth and through participation of the researchers, the degree of continuity and discontinuity as children move from preschool to 
primary education. The relationship between children's play and learning in the context of a local 3-8 curriculum is explored in detail.

McDermott, Paul A., Marley W. Watkins, Michael J. Rovine, and Samuel H. Rikoon. 2013. Assessing changes in socioemotional adjustment across early school transitions-New national scales for children at risk. Journal of School Psychology 51:97-115. [class:journalArticle] The four years of early school transition are studied for insight into the 20 percent of children known to present emotional and behavioral problems. The scales are designed to show children's growth trajectories and transitions stories over this longitudinal transition. It is a nuanced assessment for application to high-risk populations.

Spilt, Jantine L., Helma Koomen, and Linda J. Harrison. 2015. Language development in the early school years: The importance of close relationships with teachers. Developmental Psychology 51.2 (February): 185-196. [http://dx.doi.org/10.1037/a0038540] [class:journalArticle]

Communication in classroom contexts merits a closer look at teachers and children as communication partners. Drawing from the Longitudinal Study of Australian Children (LSAC) the authors find a modest effect between close teacher-child relationships and receptive language development. Given the centrality of language to learning this is an important transitions focus.

\section{School Readiness-Transitions Readiness}

In the literature the concepts of transition and readiness are closely associated. Building on the previous section which looks at children as learners, and the arguments for seeing early childhood as an educational experience in its own right, the focus on preparing children for school is antithetical to such a position. Focusing on the child's skills rather than that of receiving institutions has been part of the critique of traditional concepts of readiness: 
Whitebread and Bingham 2012 develops this further in a critical review which draws on insights from neuroscience and proposes more appropriate pedagogies. In a small-scale study White 2016 reminds us of the wide age range of young children at school entry. Some transitions literature sees readiness to learn and school readiness as flawed concepts. Graue 2006 suggests that readiness is locally relative and that ready schools are those that reach out to children, and acknowledge and respond to diversity. The Head Start Program promoted readiness, but has responded to contemporary revisions of the readiness concept, to promote present experience and not only focus on preparation for what lies ahead.. Given that increasingly school readiness is conceptualized in a variety of ways, is used as a marketing tool, is measurement heavy, and is open to many misunderstandings, attention is drawn to several factors, rather than taking a childreadiness paradigm alone. The literature suggests ready families, ready communities, ready early childhood education and care settings, and ready schools combine to give children the best possibility of being well positioned (being transitions-ready) to take advantage of schooling. Numerous ways of determining readiness have been developed — with some of them very lengthy, e.g., EDI and AEDI (see *Family Engagement*); some considered invalid as Ackerman and Barnett 2005 attests; and some, as Hatfield, et al. 2016 shows, based on classroom observations. Hughes, et al. 2015 gives us a proposal of a much briefer teacher-completion instrument from England. There has been a proliferation of public bodies publishing on readiness and transition. Research-based policy recommendations from the United States (Kagan and Rigby 2003),from international bodies such as UNICEF (UNICEF 2012), and from government departments such as Ring, et al. 2016 (Ireland) are found in many jurisdictions. Recent work combined with a focus on transitions as with OECD's Starting Strong V 2017 (see *Research, 
Policy and Practices*). It is time for a very thorough investigation of this crossover of transitions-readiness terminology, adding to the questions generated in Graue 2006. Ackerman, Debra J., and W. Steven Barnett. 2005. *Prepared for kindergarten: What does 'readiness' mean?[http://nieer.org/policy-issue/policy-report-prepared-for-kindergarten-whatdoes-readiness-mean]*. NIEER Preschool Policy Brief (March). [class:report] The authors show the difficulties in defining readiness. They set out what is known about readiness in this policy brief, and how it may be improved. They take time to address teachers' conceptions of readiness, suggest the discontinuation of "invalid tests to determine readiness for kindergarten" (p. 1) and recognize diversity among children.

Graue, Beth. 2006. The answer is readiness-Now what is the question? Early Education \& Development 17.1: 43-56. [https://doi.org/10.1207/s15566935eed1701_3] [class:journalArticle] This wonderful question continues to challenge. Graue found 117,000 hits on Google for "kindergarten readiness" in 2006. Today it is 5,750,000: a forty-nine-fold increase indicating a continuing anomaly. A refreshing "must read," Graue sets out the dilemmas and equity issues, confirming readiness as a relational concept and offering clear questions.

Hatfield, Bridget E., Margaret R. Burchinal, Robert C. Pianta, and John Sideris. 2016. Thresholds in the association between quality of teacher-child interactions and preschool children's school readiness skills. Early Childhood Research Quarterly 36: 561-571. [https://doi.org/10.1016/j.ecresq.2015.09.005] [class:journalArticle] Based on data from 222 teachers and 875 children, this paper provides evidence to understand how classroom quality and the quality of teacher-child interactions supports school-readiness. Teachers showed warmth, respect for children's autonomy and intentional interactions: where such qualities were absent, children showed less progress toward being ready for school. 
Hughes, Claire, Irenee Daly, Sarah Foley, Naomi White, and Rory T. Devine. 2015. Measuring the foundations of school readiness: Introducing a new questionnaire for teachers - The Brief Early Skills and Support Index (BESSI). British Journal of Educational Psychology 86:332-333. [class:journalArticle]

Hughes and colleagues take a multidimensional approach to school readiness. BESSI provides a one-page teacher screening tool for school readiness as a promising alternative to previous measures (appropriate for 2.5 to 5.5 years). Taking a broader perspective than purely academic skills, family support and behavioral and social competencies are included.

Kagan, Sharon Lynn, and Elizabeth Rigby. 2003. *Improving the readiness of children for school: Recommendations for state policy[http://www.cssp.org/publications/publicpolicy/policy-matters-improving-the-readiness-of-children-for-school.pdf]*. Washington, DC: Center for the Study of Social Policy. [class:report] This report begins by clarifying the confused constructs of "ready for school" and "ready to learn." Readiness relevant research of the time is summarized, the policy context of the time shows continuing lessons for the present: quality, coordination, and consistency of services and five dimensions of readiness are addressed.

Ring, Emer, Máire Mhic Mhathúna, Mary Moloney, et al. 2016. An examination of concepts of school readiness among parents and educators in Ireland. Dublin: Department of Children and Youth Affairs. [class:book]

This important research-based report generated a dynamic set of findings including recommended criteria for school start, staffing ratios in both sectors being closely aligned. The adoption of an interactionist approach and some positive elements in the readiness of special 
needs children were highlighted. Improved communication between all players was advocated. Available *online[www.dcya.ie]*.

UNICEF. 2012. *School readiness and transitions: A companion to the Child Friendly Schools Manual[https://www.unicef.org/publications/files/CFS_School_Readiness_E_web.pdf]*.New York: UNICEF Division of Communication. [class:book]

This guide explicitly links school readiness practices with transition to school: seen as a resource for preparing children and families for school and advocacy for school readiness practices it is important to know why and where "readiness" is being targeted. The benefits and costs section speaks of intrinsic and instrumental benefits.

White, Victoria. 2016. *Teacher perspectives on the season of birth effect and its influence on school readiness[http://www.leedsbeckett.ac.uk/-/media/files/riches/spotlight-volume-12016.pdf]*. Spotlight: Journal of Undergraduate Research 1.1 (September): 2-12.

[class:journalArticle]

This small-scale (four teachers) student study provides an example of promising new work. Much has been written about the challenges for younger children starting school, about retention, and about optimum ways of starting school. The wide age and developmental spread in classrooms is challenging for teachers and children.

Whitebread, David, and Sue Bingham. 2012. *School readiness: A critical review of perspectives and evidence. Occasional Paper No: 2[tactyc.org.uk/wp-content/uploads/2014/09/Bingham-andWhitebread-2012.docx]*. TACTYC: Association for Professional Development of Early Years Educators. Univ. of Cambridge. [class:report]

Expressing concern about a prevailing deficit model of school entrants and a consequent "set of inappropriate, one-size-fits-all standards of "readiness" for school" (p. 1) attractive to 
governments, this critical review of perspectives and evidence from England tackles readiness for learning, lessons from neuroscience, and appropriate pedagogical approaches with clarity.

\section{Identity as a School Child, Peer Play, and Peer Relations}

According to Barnett 2012 we are all in a continuous state of learning and therefore of transition - he refers to the "liquid learner" and the "ecological learner": both important for the fluidity of the transitions process as described here by Ackesjö 2013. Children's perceptions of self are largely informed by how others are in relation to the child: parents, siblings and the immediate family circle of friends. Hughes 2011, which is on social understanding and social lives up to the transition to school, is informative on a set of psychological processes that are not always well understood in education. As children enter out-of-home settings and in due course move to school these constructs of self are further developed in reference to the peer group, teachers, and others in the school culture. Hartup 1996 and Corsaro 2003 both illustrate the significances of friendship in creating peer-cultures and shaping identity. While true of the individual these constructs of identity can relate to educational cultures as well as discussed in *Diversity and Inclusion in Transitions to School*, and to child cultures as understood and elucidated by Corsaro's citations in this article (Corsaro 1996 [cited under *Defining Transitions: Research Approaches, Concepts, and Frameworks*], Corsaro 2003, Corsaro and Molinari 2005, Corsaro and Molinari 2008 [cited under *Research, Politics, and Practices*]). The child's cultural biography (Fisher 2009, cited under *Children as Learners*) interacts with their capacity to navigate change, the environments through which the child is making the transition and their own sense of belonging, contribution, and control. Here the role of friendships and relationships in the peer group addressed by Ladd 1990, Hartup 1996, and Peters 2003 are shown to merit 
further research as well as considered attention from professionals in education, particularly in the context of identity formation and children's well-being, which are prioritized by Warin 2010 . Ackesjö, Helena. 2013. Children crossing borders: School visits as initial incorporation rites in transition to preschool class. International Journal of Early Childhood 45.3: 387-410. [class:journalArticle]

Transition is observed to be a continuous and looping border process in the Swedish preschool class, with a lengthy period of identity construction. The idea of a contra-flow between old and new experiences, between expectations and the realities encountered on visits, indicates a need for cooperation and clarity between sectors.

Barnett, R. 2012. The coming of the ecological learner. In Transitions and transformations in learning and education. Edited by P. Tynjälä, M. -L. Stenstrom, and M. Saarnivaara, 9-20. Dordrecht, The Netherlands: Springer. [ISBN: 9789400723115] [class:bookChapter] Not specifically about early childhood transition, nevertheless given the dominance of the ecological model of transitions in early childhood work, Barnett's contribution supports a view of the ecological learner embedded in and interconnected to multiple learning contexts. Selfsustainability is dependent on mutual sustainability and provides an ethical interactive dimension.

Corsaro, William. 2003. We're friends right? Inside kid's culture. Washington, DC: Joseph Henry Press. [ISBN: 9780309087292] [class:book]

Corsaro's ethnographic studies allow a unique insight into the shared cultures young children cocreate: these are defined as "a stable set of activities or routines, artifacts, values, and concerns that kids produce and share in interaction with each other" (p. 2). The social power of shared narratives incorporate "priming" for transitions. 
Hartup, Willard W. 1996. The company they keep: Friendships and their developmental significance. Child Development 67.1:1-13. [class:journalArticle]

Content, constructiveness, closeness, symmetry, and affective profile: having friends, the identity of friends, and friendship quality are all used to describe friendship. The affordances of being friends support children's problem solving in transitions and ties with the benefits Ladd reports in his work. Hartup advocated further research on friendships. Hughes, C. 2011. Social understanding and social lives: From toddlerhood through to the transition to school. Hove, UK: Psychology Press. [ISBN: 9781841697352] [class:book] A rich data set gathered over time informs this book. Transitions to school are considered in terms of peer status, social competence, and self-concepts. The book looks at challenges of selfregulation in the new situation of the school following school start: a person-centered approach will enhance important developmental understandings.

Ladd, Gary W. 1990. Having friends, keeping friends, making friends, and being liked by peers in the classroom: Predictors of children's early school adjustment. Child Development 61.4: 1081-1100. [class:journalArticle] Ladd has continued to write extensively on children's school adjustment during educational transitions. This early article was one of the first to consider the importance of friendships between children at such times in terms of perceptions of school, adjustment to school, and favorable outcomes: these connections merit teacher attention.

Peters, Sally. 2003. "I didn't expect that I would get tons of friends ... more each day":

Children's experiences of friendship during the transition to school. Early Years 23.1: 45-53. [https://doi.org/10.1080/0957514032000045564] [class:journalArticle] 
Transitioning to school on or near to their fifth birthday may mean that New Zealand children become the sole new entrant child, or they may go with, meet up with old, or make new friends. Peters's study attends to twenty-three children's experiences of friendship in relation to school start.

Warin, Jo. 2010. Stories of self: Tracking children's identity and wellbeing through the school years. Stoke on Trent, UK: Trentham Books.

Agency, a sense of self, and its capacity for renewal are each present in this fascinating qualitative longitudinal study beginning when the participants were three years old. The work shines a light on well-being, the development of self, relationships with teachers and children's identity capital: argued as contemporary educational priorities.

\section{Continuity and Discontinuity (Well-Being, Resilience, Relationships with Educators, Care-}

\section{Givers, and Peers)}

Continuity in education has been argued as a persistent theme through philosophical, psychological, and educational thinking. Discontinuities also have their place, and the resilience to cope with discontinuity allows the building of an internal continuity for the individual. As children enter and move through our educational systems debate of the concept of continuity sharpens. At points of transition Broström 2002 tells us it is generally held to be more favorable if experiences are familiar and recognizable at the same time it is often argued that they should not be lacking in variety. Here lies a contradiction: to bridge the gap, or to narrow the gap? The earliest works on transitions in early childhood focused on narrowing the gap, in an attempt to provide continuity of experience for children (Cleave 1982, cited under *History*). There is research to suggest that by building friendships, well-being, and resilience within the child, this will strengthen the child's capacity to cope with discontinuity in the changes they meet. Each 
needs to be understood for the relative advantages and disadvantages to the child. Work on emotional well-being in the transition to school has suggested that more securely attached children are able to make more positive and supportive relationships with their peers and with teachers: de Groot Kim 2010 shows how practice can fly in the face of such knowledge. Evidence suggests the relationship with the first teacher is an indicator of later school success or at least implicated in positive trajectories through school(Harrison, et al. 2007; Hatfield, et al. 2016, cited under *School Readiness*; and Spilt, et al. 2015, cited under *Children as

Learners*). If some children are more able to create new relationships than others, then differentiated support may be needed at times of transitions. In attachment security terms this underlines the importance of ensuring children are set up to create positive relationships with adults and peers, and secondly, if they are not, that support is invested in nurturing positive relationships during early childhood, so potentially resolving one of the barriers to positive school experiences. Dunlop 1998 argues a creative approach to understanding what children bring to the school experience and their agency through a holistic home-based assessment, while Di Santo and Berman 2012 advocates a move to viewing children as competent actors, as does Babić 2017 in her challenging article, thus perhaps avoiding the "backward break" that Oskarsdóttir 2012 found. Munz and Wilson 2014 affirms the role of parents in supporting continuity.

Babić, Nada. 2017. Continuity and discontinuity in education: Example of transition from preschool to school. Early Child Development and Care 187.10: 1596-1609. [doi:10.1080/03004430.2017.1301935] [class:journalArticle] This challenging article interrogates the rhetoric of children's agency and explores their expressed perceptions of what happens in school, finding children align with adult views. It 
discusses whether it is possible to access the child's own view, continuities, and discontinuities and proposes a "pedagogy of dialogue" rather than teacher-direction.

Broström, Stig. 2002. Communication and continuity in the transition from kindergarten to school. In Transitions in the early years. Debating continuity and progression for young children in early education. Edited by Hilary Fabian and Aline-Wendy Dunlop, 52-63. London: RoutledgeFalmer. [ISBN: 9780415276399] [class:bookChapter] This chapter coined a new concept of children feeling "suitable in school" which perfectly captures the importance of children feeling familiar enough with the new setting into which they transition in order to benefit from the school experiences. Broström researched transitions activities and their application in America and Denmark. de Groot Kim, Sonja. 2010. There’s Elly, it must be Tuesday: Discontinuity in child care programs and its impact on the development of peer relationships in young children. Early Childhood Education Journal 38:153-164. [class:journalArticle] Continuity of experience is influenced by extant policies in any given setting: decisions about transitions in and out of classrooms, the number of days of attendance, and lack of attention to competence in friendships between a stable group of peers, fly in the face of knowledge about the development of relationships.

Di Santo, Aurelia, and Rachel Berman. 2012. Beyond the preschool years: Children's perceptions about starting kindergarten. Children and Society 26:469-479. [class:journalArticle] In Ontario, Canada, the Ministry used EDI as an evaluation of outcome measure for children enrolled in their new two-year kindergarten project. In this paper the authors propose a move from a developmentalist view of children to seeing them as competent active agents in their own relationships, learning, and transitions. 
Dunlop, A.-W. 1998. Assessment as part of a continuity study. Early Years: An International Research Journal 19.1: 39-49. [class:journalArticle]

Recognizing that assessment was increasingly being used to determine the added value of investing in preschool education, this early transitions-focused article proposes a sympathetic and authentic means of assessment through a story book approach that allows the recognition of the funds of knowledge and dispositions that children bring to school.

Harrison, Linda J., Leanne Clarke, and Judy A. Ungerer. 2007. Children's drawings provide a new perspective on teacher-child relationship quality and school adjustment. Early Childhood Research Quarterly 22:55-71. [class:journalArticle]

Given the literature on the importance of relationships as a foundation for positive transitions and later school success, a study which looks at both direct (child self-report) and indirect (through drawings) data about such relationships, insecurities, and adjustment in school, and provides an important window on key elements of transition.

Munz, Elizabeth A., and Steven R. Wilson. 2014. Caregiver confirmation and children's attachment security during the transition to kindergarten. Communication Research 44.5: 668690. [class:journalArticle]

On the basis that caregivers "play a crucial role in helping their children's transition" (p. 669), Munz and Wilson investigated the extent to which primary caregivers encouraged "child openness" (p. 669) in the transition to kindergarten. The importance of caregivers' confirming children's feelings positively influence their experiences during transition.

Oskarsdóttir, Gerður G. 2012. Educational transitions: Continuity or discontinuity. PhD diss., Univ. of Iceland, School of Education. [class:thesis-phd] 
Dewey's theory on continuity of experience in education provides the theoretical framing for this study, which investigates three dimensions of continuity versus discontinuity: school structures, methods of teaching and learning, and the links and relationships between school levels.

Institutional features and a curriculum "backward break" appeared to have the greatest influence.

\section{Research, Policy, and Practices}

In this section a selection of work that in different ways relates to this last issue of the relationship, in this recognized field of early childhood/early educational transitions, of the three elements of research, policy, and practice, is offered. In the light of Dewey's theory of continuity of experience in education (see note below) we could ask the question, "Why are we are still studying early childhood transitions across the world so long after the historical studies of the 1980s set out a range of key issues that needed then to be addressed in policy and practice?" As evidenced in this article, many of these issues continue to be studied today. New generations of researchers return to, for example, relationships between early childhood settings and school, practitioner knowledge, the engagement of parents, the nature of curriculum, readiness for school, professional education, children's relationships with peers in transitions, sociocultural knowledge, the value of a relational play-based pedagogy, the quality, synchrony, and continuity of practices in early childhood and elementary school, the resilience and well-being of today's children, and the influencing factors between research, policymaking, and day-to-day practices. Policy operates across different layers of school-based, local, regional, and national decision making. International bodies concerned with country comparisons have become alert to the ways in which a child's transition may bring benefits or exacerbate disadvantage (UNICEF 2008; OECD 2017). Work in rich nations often stands separately from nations struggling to create change, faced with massive poverty and many inequities to which Margetts and Phatudi 2013 
draws attention. Sparkles of rich, thoughtful, agentic practice stand out in the ethnographic work of Corsaro and Molinari 2008 in Italy, with many implications for good communications, shared agendas, and respect for children and the peer cultures they create. In the interests of high quality, positive sharing and promotion of the importance of transitions for children, their families and those that work with them, Dunlop 2017, Wallis and Dockett 2015, the Educational Transitions and Change (ETC) Research Group 2011, and the Transitions Summit Guide of the National Center on Quality Learning and Teaching (NCQTL 2014) each propose significant new approaches to networking and community building around transitions. Embedded in all of these approaches must be a concern for social justice and equity. (Note: Dewey asserts that "the principle of continuity of experience means that every experience both takes up something from those which have gone before and modifies in some way the quality of those which come after” (John Dewey, Experience and Education. New York: Collier Books, 1963, p. 35): arguably central to understandings of continuity and discontinuity in early educational transitions).

Corsaro, William, and Luisa Molinari. 2008. Policy and practice in Italian children's transition from preschool to elementary school. Research in Comparative and International Education 3.3: 250-265. [class:journalArticle]

With a strong focus on the collective experience of preschool and the importance of group discussion, peer culture, and children's production of routines as priming events providing continuity in transition to elementary school, this rich study shows how local school policy affects transitions and supports the roles children themselves play within that. Dunlop, Aline-Wendy. 2017. Transitions as a tool for change. In Pedagogies of educational transitions, European and Antipodean Research. Edited by N. Ballam, B. Perry, and A. 
Garpelin, 257-273. Dordrecht, The Netherlands: Springer. [ISBN: 9783319431185]

[class:bookChapter]

In Scotland researchers, policymakers, practitioners, and university tutors are engaged in a research-practice cooperation based on a novel concept of "transitions as tools for change" bringing together three themes: children's learning journeys, professional beliefs and practices, and family engagement at times of transition to inform policy and practice decisions.

Educational Transitions and Change (ETC) Research Group. 2011. *Transition to school: Position statement[http://www.csu.edu.au/faculty/educat/edu/transitions/publications/PositionStatement.pdf]*. Albury-Wodonga, Australia: Research Institute for Professional Practice, Learning and Education, Charles Sturt Univ. (CSU). [class:report]

The position statement generated during a week-long seminar event at CSU models a productive engagement between researchers, practitioners, and policymakers at local, state, and international levels. Four widely relevant principles attending to aspirations, expectations, opportunities, and entitlements support a view of the child as competent, capable, and creative.

Margetts, Kay, and Nkidi Caroline Phatudi. 2013. Transition of children from preschool and home contexts to grade 1 in two township primary schools in South Africa. European Early Childhood Education Research Journal 21.1: 39-52.

[https://doi.org/10.1080/1350293X.2012.760341] [class:journalArticle]

Implementing national policy at the local level can be challenging, but national policy can bring impetus to early childhood education to foster learning and preparedness for school in a disparate and unequal service provision, which is acknowledged to need more focus upon the positive role ECE can play in future learning. 
National Center on Quality Learning and Teaching (NCQTL). 2014. *Transition to kindergarten: Transition and Alignment Summit

Guide[https://eclkc.ohs.acf.hhs.gov/sites/default/files/pdf/transition-summit-guide.pdf]*. [class:report]

The concept of a transitions summit may appeal to those concerned about early transitions experiences and how to make them work well for children and families. Transitions occur as a way of life for all children, but those with adverse childhood experiences have a right to particular relationship-based support.

OECD. 2017. Starting Strong V. Transitions from early childhood education and care to primary school. Paris: OECD. [ISBN: 9789264276239] [class:book]

As evidenced in this OECD report dedicated to early transitions, political, social, research, and practice attention on early childhood transitions has grown in recent years. Investment in early childhood provision means governments monitor the quality of early childhood experiences and need to see the claimed benefits in the school years.

UNICEF Innocenti Research Centre. 2008. The child care transition: A league table of early childhood education and care in economically advanced countries. Report Card 8. Florence: UNICEF Innocenti Research Centre. [ISBN: 9788889129708] [class:book]

This is one of the few resources included here that recognizes the huge transition and transformation going on in early childhood services, particularly in rich countries where children are spending a large part of their time in out-of-home childcare. Consequently a huge question is the balance of opportunity and risk. 
Wallis, J., and S. Dockett. 2015. Stakeholders, networks and links in early childhood policy: Network analysis and the Transition to School: Position Statement. Contemporary Issues in Early Childhood 16.4: 339-354. [class:journalArticle] An excitingly original contemporary contribution to the literature on the potential of transitions research-policy digital connections. Raises important questions about the impact of research and practice on transitions policy even when it has a digital presence. Government sites dominate in network analysis and therefore shape narratives with a public influence. 